\title{
Confiança na polícia em Minas Gerais: o efeito da percepção de eficiência e do contato individual
}

\begin{tabular}{c}
\hline \hline Geélison F. Silva \\
Doutorando em Ciência Política \\
Universidade Federal de Minas Gerais \\
Cláudio Beato \\
Departamento de Sociologia e \\
Centro de Estudos de Criminalidade \\
e Segurança Pública - UFMG \\
\hline \hline
\end{tabular}

Resumo: $\mathrm{O}$ artigo busca identificar e analisar os principais fatores que impactam a confiança na polícia em Minas Gerais. Utilizou-se a pesquisa "Vitimização e Percepção de Medo em Belo Horizonte e Minas Gerais" de 2009, aplicada em 29 municípios. Além de Belo Horizonte, abrangeu 5 cidades da Região Metropolitana, 7 cidades consideradas polos regionais e 16 municípios com população inferior a 10 mil habitantes. Os resultados mostram que indivíduos confundem funções do trabalho policial com as do sistema de justiça criminal. O contato com a polícia reduz a confiança, especialmente quando ele é iniciado por policiais. Nas cidades menores, onde a polícia é mais próxima dos cidadãos e a criminalidade é menor, a polícia recebe mais confiança do que nas maiores. A percepção de eficiência em solucionar problemas relacionados à violência é a variável que produz maior efeito positivo no nível de confiança que a instituição recebe.

Palavras-chave: confiança; polícia; percepção de medo; Minas Gerais/Brasil

Abstract: In this article, we aim to identify and analyze key factors impacting trust in the Minas Gerais State Police. To achieve this goal, we used the survey "Victimization and Fear Perception in Belo Horizonte and Minas Gerais", 2009, conducted in 29 cities. Apart from Belo Horizonte, the survey covered 5 cities in its metropolitan area, 7 cities considered regional poles and 16 other towns with less than 10,000 inhabitants. Some of the results are: individuals confuse police's functions with criminal justice's system's functions; individuals with lower socioeconomic status, that suffer greater police repression, are those who most trust the police; in smaller towns, where the police has closer contact to citizens and criminality is reduced, the police receives more trust than in larger ones; the perception of efficiency in solving problems related to violence produces the biggest positive effects on the level of institutional trust.

Keywords: trust; police; fear perception; Minas Gerais/Brazil 
SILVA, G. F.; BEATO, C. Confiança na polícia em Minas Gerais: o efeito da percepção... Introdução ${ }^{1}$

É extenso e divergente o debate sobre o papel do apoio e legitimidade das instituições, especialmente em regimes democráticos. Enquanto muitos autores percebem a baixa legitimidade como um risco para as instituições, outros consideram que isso as torna mais eficientes (Molsés, 2008; NoRRIS, 1999; RENNÓ et al, 2011; Seligson et al, 2006). A confiança institucional é considerada um dos principais indicadores de legitimidade, mas, sobre ela também não há consenso acerca do possível papel positivo para o melhor funcionamento das instituições. É provável que um posicionamento crítico produza melhores resultados no desempenho institucional do que uma confiança cega (NoRRIS, 1999; MoısÉs, 2008). A despeito do debate polêmico acerca da confiança nas instituições em geral, tratando. se da polícia, há maior acordo sobre seu impacto positivo, dada sua necessidade para a cooperação que é essencial ao trabalho policial. O principal objetivo deste artigo é explorar os efeitos de algumas das principais variáveis citadas pela literatura como as que mais impactam a confiança, logo, a legitimidade da polícia. São mensurados os efeitos do contato dos indivíduos com a instituição, a percepção de eficiência/desempenho, o tipo de cidade, além de características socioeconômicas. Ressaltamos que este artigo não busca responder se a confiança é de fato benéfica ao funcionamento da instituição em voga; isso é praticamente um consenso na literatura internacional, apesar de existirem raros trabalhos sobre o tema publicados no Brasil. Como não sabemos que fatores aumentam ou diminuem a confiança na polícia, pretendemos avançar nesse campo.

A desconfiança popular nas instituições policiais é recorrente nos países da América Latina, especialmente naqueles que saíram do autoritarismo recentemente. No Brasil, a proporção de pessoas que têm mais medo da polícia do que de bandidos chega a 56\%; na Argentina, essa proporção atinge $19,3 \%$ da população (e entre os adolescentes, $37 \%$ ). Ainda, $26 \%$ concordam com a afirmação segundo a qual os policiais estão entre os mais delinquentes. Em El Salvador, $22 \%$ consideram que a polícia não respeita, em absoluto, os direitos humanos (KAHN, 2003).

A partir do World Values Survey - WVS (2011) encontra-se que, dentre 47 países analisados, o Brasil é o trigésimo quarto em nível de confiança na polícia. Enquanto nos três países com maior grau de confiança, mais de $90 \%$ dos cidadãos tendem a confiar na polícia, no Brasil, esse percentual é de apenas $44,9 \%^{2}$. O percentual médio de pessoas que tendem a confiar na polícia nos 47 países pesquisados é $58,4 \%$ (SILVA \& BRAGA, 2012).

Roberts (2007, p. 166) problematiza a confiança nas instituições de justiça, inclusive na polícia. Um complicador para que ela ocorra está no fato de lidar diretamente com partes divergentes, como por exemplo, a vítima e o suspeito, o que pode prejudicar seus níveis ao serem comparadas com outras instituições. Entretanto, isso não impede que, no Canadá por exemplo, dentre as instituições do sistema de justiça, a polícia seja a que recebe maior nível de confiança e é tida como a maior aliada da

\footnotetext{
${ }^{1}$ Este artigo também é, em parte, reformulação da dissertação do primeiro autor, intitulada "A confiança na polícia em Minas Gerais: o que importa?", orientada pelo segundo autor e apresentada ao Programa de Pós-Graduação em Sociologia da Universidade Federal de Minas Gerais. Por isso, é fundamental o agradecimento a Fundação de Amparo a Pesquisa do Estado de Minas Gerais (FAPEMIG) pela bolsa de pesquisa e ao Centro de Estudos de Criminalidade e Segurança Pública (CRISP) pela disponibilização dos dados. Também aos demais professores que contribuíram com o trabalho: Andrea Maria Silveira e Corinne Davis Rodrigues que participaram da banca de qualificação e a Arthur Trindade Maranhão Costa e Ludmila Mendonça Lopes Ribeiro pela participação na banca de dissertação. Agradecemos aos vários colegas que deram valiosas sugestões. Ressaltamos, porém, que as possíveis falhas são nossas.

${ }^{2}$ Pesquisa do IPEA (2011) encontra que apenas 25\% da população brasileira confia na polícia enquanto 75\% não confiam. Variações dos indicadores de confiança são justificadas pela utilização de métodos diferentes e realização das pesquisas em datas diversas. Apesar das diferenças, é possível identificar tendências ao se comparar os países, regiões ou estados.
} 
população, especialmente no combate ao crime. Esse alto índice é atribuído ao cumprimento padronizado dos procedimentos e à forte regulação pelas cortes e constituições. A Finlândia, como os demais países nórdicos, tem alto nível de confiança policial comparado com outros países, mesmo europeus. Isso é atribuído à eficiência do trabalho policial, à proximidade da polícia à comunidade e à qualidade do serviço prestado. Apenas $5 \%$ da população afirmam confiar pouco ou muito pouco na polícia (KÄÄRIÄINEN, 2008, p. 141; 145).

No Brasil, de acordo com dados do IPEA (2011), a região sudeste é a que possui menor grau de confiança (75\% afirmam confiar pouco ou não confiar na polícia (IPEA, 2011)). Em relação à polícia civil, de acordo com dados publicados pelo IPEA (2010), tem-se que $4 \%$ confiam muito, $26,1 \%$ confiam, $44 \%$ confiam pouco e 25,9\% não confiam. Logo, 69,9\% da população apresentam algum grau de desconfiança em relação à Polícia Civil no Brasil (RIBEIRO \& SILVA, 2010, p. 179; 190).

No estado do Rio de Janeiro, apenas 7,3\% de pessoas afirmaram confiar ou confiar totalmente na polícia militar (LIMA, 2009). Isso é menos da metade da proporção de pessoas que tendem a confiar na polícia no Peru $(15,7 \%)$, país com menor percentual de cidadãos que confiam na polícia segundo o WVS (2011). Com relação à polícia civil do Rio de Janeiro, 9,7\% confiam, de acordo com pesquisa do Instituto de Segurança Pública no Rio de Janeiro - ISP (LIMA, 2009). No estado do Espírito Santo, em $2009,62 \%$ dos entrevistados afirmaram confiar pouco ou não confiar e $36 \%$ confiar muito ou confiar (PANSINI, 2009).

No estado de Minas Gerais, de acordo com pesquisas realizadas pelo Centro de Estudos de Criminalidade e Segurança Pública (CRISP) da UFMG nos anos de 2008 e 2009, o nível de confiança na polícia é mais elevado do que no país como um todo, com ligeiro aumento do primeiro para o segundo ano. Em 2008, 64\% dos entrevistados afirmaram confiar muito ou razoavelmente naquela instituição. Esse percentual subiu para $67 \%$ em 2009. A proporção dos que afirmaram não confiar ou confiar pouco na polícia caiu de 36\% em 2008 para 33\% em 2009.

Estudos apontam que as instituições na América Latina, e em especial no Brasil, recebem baixo grau de confiança (MoIsÉs, 2005; ROTHSTEIN \& USLANER, 2005). No caso de Minas Gerais, dentre 7 instituições pesquisadas, a polícia é a terceira menos confiável, recebendo menor grau de confiança do que os governos estadual e federal, mesmo com o alto desprestígio que os políticos possuem. Pode-se dizer que o nível de confiança que a polícia mineira recebe aproxima-se do de países como Japão, Índia e Espanha, mas está bastante aquém do que recebe na Jordânia, Finlândia, Vietnã e Noruega. Em Minas Gerais, é pouco superior à confiança nos governos municipais e poder judiciário e consideravelmente inferior à Igreja (SILVA, 2012).

Para a população, e mesmo para a maioria dos policiais, a função da polícia é enfrentar o crime. Logo, está atrelada à função do sistema de justiça criminal. Entretanto, atividades desse tipo ocupam parte reduzida do tempo de trabalho policial (GoldSTEIN, 2003; MUNIZ, 2006; SANTOS, 2012). Nesse sentido, estabelece-se a hipótese de que a confiança prestada à instituição policial está fundamentalmente relacionada à percepção de que ela combate o crime com eficiência. Quanto mais eficiente demonstrar ser a polícia nessa tarefa maior grau de confiança receberá.

De acordo com Tyler (2005), além da observação instrumental que leva em conta a utilidade e a eficiência da polícia em cumprir seu papel, os indivíduos também se pautam nos procedimentos de 
SILVA, G. F.; BEATO, C. Confiança na polícia em Minas Gerais: o efeito da percepção...

justiça e igualdade para construir sua percepção. No caso brasileiro, a relação entre polícia e sociedade é problemática, tendo em vista a reminiscência de ranços do regime militar e a desigualdade de tratamento, atuando com um viés repressivo sobre os mais pobres (MISSE, 2007; PAIXÃO, 1990; SILVA, 2009). Considera-se que em boa medida a polícia é autoritária, militarizada, violenta e despreparada para atender aos cidadãos (CANO, 2011).

O objetivo deste artigo, que figura entre os primeiros do Brasil que tratam especificamente da confiança na polícia, é contribuir para a formação de um campo e assim permitir identificar e analisar os principais aspectos que interferem na legitimidade policial brasileira. Dentre as variáveis que são consideradas no artigo estão as condições socioeconômicas, tipo de contato que o indivíduo tem com a instituição policial (que pode ser direto (pessoal) e indireto (por terceiros e mídia)) e também tem potencial de afetar a confiança nas instituições (HUDSON, 2006). O fato de que os indivíduos com menor status socioeconômico confiem mais na polícia a despeito de sofrerem mais com sua ação repressiva pode ser mediado por variáveis de contato. 0 contato com a polícia também é diferente quando iniciado pelo cidadão ou pela polícia, sendo que, no primeiro caso, a relação tende a ser menos conflituosa, permitindo maior confiança.

\section{A importância da confiança na polícia}

Apesar de a literatura sobre cultura política não expressar consenso acerca do papel positivo ou negativo da legitimidade e confiança das instituições políticas (MoIsÉs, 2008; NORRIS, 1999; RENNó et al, 2011; SELIGSON et al, 2006), estudos sobre a polícia consideram a confiança importante para que a instituição seja eficiente. A instituição policial, especialmente quando lida com investigação e controle do crime, está entre aquelas que mais dependem da cooperação dos indivíduos. A cooperação varia de acordo com o grau de legitimidade que possui. Quando o nível de confiança na instituição policial é baixo, há maior tendência de que as comunidades percebam as ações da polícia como ilegítimas (HUdson, 2006; ROthSTeIN, Uslaner, 2005; StOUtLANd, 2001).

A importância da confiança na instituição policial está presente de forma difusa em todo o artigo. Mas, considera-se relevante explicitá-la relacionando os principais motivos da sua relevância citados pelos pesquisadores consultados, inclusive por esse tema ser raramente pesquisado no Brasil. Tal importância passa pelo favorecimento à cooperação dos cidadãos com a instituição, realização de registros de ocorrências criminais, chegando a um ciclo positivo em que a confiança favorece a eficiência policial que, por sua vez, corrobora a confiança (BROWN \& BENEDICT, 2002; CAO, 2011;

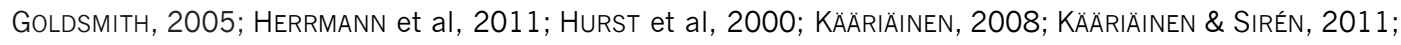
Magalmães, 2003; Moisés, 2005; Myhill \& Beak, 2008; Oliveira, 2011; PaixÃo \& Beato, 1997; Roberts, 2007; Skogan, 1984; TANKebe, 2010; Tyler \& Wakslak, 2004; Tyler \& Fagan, 2008; Wiatrowski \& Goldstone, 2010).

A confiança nas instituições policiais é apontada como fundamental em países democráticos. Em sociedades autoritárias, é comum negligência ou abusos da polícia com os cidadãos. Também são recorrentes incompetência, desonestidade e ausência de benevolência. Tem-se o distanciamento do Estado como prejudicial para o relacionamento com o público (GOLDSMITH, 2005, p. 448).

O sistema de justiça como um todo, bem como a polícia, depende do público para ser eficiente. A opinião pública contribui para reformular mudanças na instituição, direcionar recursos 
segundo interesses coletivos e motivar a implementação de novos programas ou a alteração de antigos. É usada para a avaliação da performance e a confiança sinaliza a eficiência (HURST et al, 2000).

Quando se confia na polícia há maior probabilidade de aceitação de suas decisões e acredita. se que elas são tomadas de forma neutra (TYLER \& WAKSLAK, 2004, p. 258). Para Costa (2004a, p. 95), quanto maior a percepção de legitimidade da polícia mais facilmente é aceita a sua autoridade, reduzindo a necessidade de se recorrer à violência. Aceita-se mais facilmente a autoridade do Estado na solução dos conflitos.

Quando o nível de confiança na instituição policial é baixo, há maior tendência a que as comunidades percebam as ações da polícia como ilegítimas, dificultando a cooperação e uma atuação eficiente, pois o controle do crime não depende meramente da ação isolada da polícia, mas também da cooperação da comunidade (HUdSON, 2006; ROTHSTEIN \& USLANER, 2005; STOUTLAND, 2001). De acordo com Myhill \& Beak (2008), a legitimidade está associada à propensão a cooperar. Para Tankebe (2010, p. 298), a confiança é a pedra angular da cooperação e a base da legitimidade da polícia em sociedades democráticas. Favorece o cumprimento da lei e a cooperação com as autoridades legais.

\footnotetext{
"A autoridade legítima, quando existe, tem uma vantagem única e importante quando se motiva a cooperação voluntária que não é dependente de critérios instrumentais. Na medida em que as pessoas são motivadas pela legitimidade, cooperam porque sentem que é a coisa certa a fazer, não por causa de ganhos ou perdas materiais" (TYLER \& FAGAN, 2008, p. 240).
}

Uma das formas apontadas como capazes de aumentar o controle sobre a polícia e melhorar a sua relação com a comunidade é criarem-se práticas e políticas que promovam o apoio do público. A impressão que o público tem da polícia é considerada fundamental para sua eficiência. Quando tal impressão é negativa contribui para um ciclo em que há redução de eficiência da polícia, aumento do crime, e desconfiança. A polícia precisa se preocupar em como ela é vista pelo público, pois deve servir ao público (BRown \& BENEDICT, 2002, p. 545-546).

A confiança pode fazer a polícia mais eficiente, pois propicia que os cidadãos reportem os crimes e cooperem para ajudar a solucioná-los. Evidentemente, a polícia necessita da cooperação dos cidadãos tanto para reportar quanto para tentar solucionar eventos criminais (KäÄRIÄINEN, 2008, p.144). Logo, enquanto a percepção negativa torna a polícia ineficiente, a positiva, pela cooperação, torna o policiamento viável (OLIVEIRA, 2011, p.07.08). Reduzir as taxas criminais e construir comunidades seguras é mais hábil quando há cooperação (TYLER \& FAGAN, 2008, p. 233).

Os indivíduos que confiam na polícia tendem a aprovar as suas ações com maior facilidade, mas quando ela é eficiente recebe ainda maior confiança. Assim, a confiança pode ser um indicativo de que a instituição é eficaz, além de expressar consonância entre a ética da polícia e a dos cidadãos (KÄÄRIÄINEN, 2008).

A confiança também é um dos fatores que influenciam os registros criminais, pois minimiza o ônus do acionamento. Considera-se que o acionamento à polícia seja uma decisão racional que o indivíduo toma levando em conta custos e benefícios. Por isso que quanto maior é a gravidade do crime maior é a chance de registrá-lo. Muito da variação do registro é explicada pelo tipo de incidente, 
SILVA, G. F.; BEATO, C. Confiança na polícia em Minas Gerais: o efeito da percepção...

havendo maior tendência em reportarem-se os mais graves. Por vezes, o custo do acionamento da autoridade é inferior ao benefício, dependendo da perda em um roubo, por exemplo, e a probabilidade de recuperar o bem (SKOGAN, 1984).

A decisão de fazer um registro policial tem caráter instrumental/racional (TYLER \& FAGAN, 2008). Relacionamento hostil entre polícia e cidadão, medo ou suspeita de que não prestará bom serviço ou de não ser bem tratado reduzem as chances de reportagem. O cálculo feito leva em conta os benefícios e prejuízos que envolvem a polícia, mas também as partes envolvidas e a comunidade (SKoGAN, 1984, p. 114; 122-123).

Considera-se que o cidadão tem o dever de reportar o crime se deseja preveni-lo no futuro, mas, em seu cálculo, pode pesar o curto prazo. Isso é evidenciado pela correlação existente entre a frequência dos crimes solucionados e a proporção registrada. Quando se acredita que o crime será resolvido e o ofensor punido, ou seja, quando há uma crença positiva sobre a eficiência, inclusive da polícia, tem-se maior probabilidade de registro. Não se reporta quando se acredita que "não se pode fazer nada" ou que "a polícia não pode fazer nada" (SKoGan, 1984).

Paixão \& Beato, baseados na Pesquisa Nacional de Domicílios - PNAD (1988), encontraram que $12 \%$ dos entrevistados não acionavam a polícia por não a quererem envolvida. "[...] não se trata propriamente de desconfiança em relação à atuação policial, mas de uma avaliação da conveniência dessa atuação: nem todos os conflitos requerem a atuação da força policial, pois podem ser resolvidos privadamente" (PAIXÃo \& BEATO, 1997, p. 242). Porém, por volta de 25\% dos entrevistados não acionaram a polícia por não acreditarem nela.

Padrões de incidência do crime direcionam a atuação policial, interferindo nos registros policiais. Como a polícia pauta suas ações de prevenção em registros, o policiamento é direcionado para localidades com maior tendência à reportagem de incidentes criminais. Mesmo quando há crime, a ausência de registros provoca o arrefecimento do policiamento, o que contribui para o aumento ou manutenção da criminalidade (SKOGAN, 1984).

De acordo com Cao (2011, p. 02), várias pesquisas têm mostrado que a confiança dos cidadãos na polícia dos Estados Unidos está associada à propensão dos indivíduos em reportarem crimes, compartilharem informações sobre atividades criminais e permanecerem em conformidade com a lei. Mesmo quando a confiança não favorece a reportagem, contribui para a coesão social e bem-estar econômico e contribui para o controle social informal (KÄÄRIÄINEN \& SIRÉN, 2011, p. 67).

É evidente que não reportar crimes traz consequências. Dentre elas, estão a não disposição de testemunhas e a impossibilidade de investigação. Ao não se registrar os crimes menos graves fomentase a motivação da prática dos mais graves. Afinal, é sabido que, geralmente, são os ofensores de pequenos delitos que cometem os mais significativos quando não são antecipadamente repreendidos (SkOGAN, 1984). Ademais, quando os conflitos são resolvidos privadamente, sem a participação do Estado, é maior a probabilidade de que se use violência na tentativa de solucioná-los.

A participação pública é tida como fundamental para o processamento de acusados, cooperação dos reclamantes, testemunhas e jurados. Daí a importância de os policy makers serem informados quando o nível de confiança cai. Primeiro, porque o nível de satisfação com o sistema está 
associado à confiança, segundo, por que a confiança policial pode afetar, inclusive, o funcionamento do sistema de justiça criminal (ROBERTS, 2007, p. 154).

Em suma, a confiança favorece a legitimidade da instituição policial e a cooperação dos cidadãos com ela. Pode contribuir para a maior predisposição dos cidadãos em registrar crimes, aumentar a coesão social e o controle social informal. Tanto é um sinal quanto potencializa a eficácia da polícia.

\section{A natureza do trabalho da polícia e seus dilemas}

A dimensão política da polícia é identificada desde a etimologia do termo, que, de acordo com Costa (2004a, p. 93), tem como origem o termo grego Polis, tal como política. Diz respeito ao exercício da autoridade coletiva. Duas dimensões importantes são ressaltadas no desempenho da função policial: o dever de exercer o controle social e a possibilidade de uso da força no cotidiano, embora a polícia realize uma série de atividades não necessariamente ligadas a esses aspectos.

Destacam-se a complexidade e a amplitude da função policial em razão das muitas incumbências e conflitos encontrados no exercício da sua função. Isso faz com que qualquer definição do que é o trabalho policial deixe de considerar algum aspecto importante. Tal complexidade começa pela dependência da polícia para com o sistema de justiça criminal. A necessidade de utilização do sistema confere a associação das atividades policiais a transgressões penais. Daí a tendência da polícia em classificar grande proporção das atividades como ligadas à criminalidade. Esta ligação da polícia com o sistema de justiça criminal faz com que, no imaginário popular, os dois sejam entendidos como a mesma coisa (GoLDSTEIN, 2003; SANTOS, 2012).

Há contraste entre o trabalho policial e as operações do sistema de justiça, principalmente, por gastar a maior parte do tempo tratando de assuntos não relacionados ao crime. Atende a pedidos de socorro, cuida de acidentes e pessoas doentes, animais feridos e perdidos, pessoas embriagadas e drogadas, trata de distúrbios familiares, brigas de gangues, reuniões barulhentas, registros de danos à propriedade, acidentes de trânsito, desaparecidos, achados e perdidos e controle de multidões. Áreas pobres são o principal campo de atuação, desempenhando papel assistencialista. Apesar disso, até policiais descrevem de maneira pobre as suas atividades (GOLDSTEIN, 2003; SANTOS, 2012).

Para Costa (2004a), diversos setores da sociedade aceitam a ideia de que há "tensão entre a manutenção da ordem e o exercício democrático do poder por parte das polícias" (COSTA, 2004a, p. 94). $\mathrm{O}$ aumento da criminalidade pode favorecer esse endurecimento das práticas policiais em que a força é usada como tentativa de controle social. Dilemas semelhantes ocorreriam ou teriam ocorrido em outros países. Para Emisley (2002), durante o século XIX, a Inglaterra realizava punição de forma seletiva ao enfrentar a desordem e tentar controlar motins. Nos Estados Unidos, Wacquant (1999) aponta para o aumento da população prisional, sobretudo de negros, indicando viés seletivo da polícia ao combater o crime e prender suspeitos. De acordo com Taxman et al (2005), minorias étnicas constituem cerca de metade da população no sistema de controle correcional, mas a soma dessa população no país é de apenas $27 \%$.

Para Ribeiro et al (2005, p. 295), na tentativa de manter a ordem pública, tem-se um processo de construção da estrutura burocrática da polícia como uma instituição total a fim de se controlar os membros da própria instituição. O modelo organizacional da polícia, segundo Paixão (1997, 
SILVA, G. F.; BEATO, C. Confiança na polícia em Minas Gerais: o efeito da percepção...

p. 188-189), é quase militar, o que impediria a sua captura por interesses militares como também inibiria o seu uso político e dificultaria a implantação de um chamado Estado policial.

Entretanto, há dificuldade de controle externo sobre a organização e possibilidade de corrupção e violência dos policiais de ponta em atividades rotineiras nas ruas. A polícia possui caráter discricionário. Na prática, significa dizer que é a polícia quem resolve o dilema entre a lei e a ordem, designando o cumprimento da lei para as classes médias e aplicando a ordem sobre "favelas", minorias étnicas, "zonas" e jovens, baseando-se em julgamentos formulados por valores de grupos "não desviantes" (PAIXÃO, 1997, p. 188-189).

Para Muniz (2006), a discricionariedade da ação da polícia é uma práxis imprescindível na profissão policial no Estado democrático apesar de que, para muitos, ela favoreça a aplicação seletiva da lei. Pode-se tratar de escolhas entre ação ou inação da parte dos agentes ou organizações. Essa característica não é exclusividade da organização policial, mas tem como aspecto mais relevante a potencialidade de interferência na liberdade dos cidadãos.

Haveria a "polícia de gente" em contraposição à "polícia de moleque". Esta última faria uso instrumental da violência ao buscar controlar o crime. Ainda, supressão dos direitos civis e falta de agilidade nas respostas. Isso prejudica a realização dos direitos civis, características que devem estar presentes no controle social do Estado democrático (PAIXÃo \& BEATO, 1997, p. 233).

Boa parte da literatura que trata de controle social e repressão ao crime enfoca a diferenciação de tratamento das instituições de controle sobre grupos e estratos sociais. A polícia é vista como agente de contenção de massas através da força. Há, entretanto, outra perspectiva na qual policiais prestariam serviços à população pobre, o que seria percebido, muitas vezes, como único serviço do Estado a chegar às áreas marginalizadas. Se, em uma perspectiva, espera-se que a população com menor status socioeconômico confie menos na polícia, na outra se espera o contrário (BOWLING \& FOSTER, 2002).

Características organizacionais, históricas e culturais da instituição policial contribuiriam para o baixo nível de confiança que ela recebe na América Latina como um todo, e em especial no Brasil. Está presente na organização um modelo estatal de controle social descrito por "estatutos, regulamentos e manuais", porém, boa parte das práticas cotidianas resultam da "cultura institucional e são transmitidas pelos processos de socialização a que estão submetidos os membros das organizações policiais". Os processos institucionalizados são - seja pelos documentos, cultura ou história - difíceis de serem transformados (COSTA, 2008, p. 411; SANTOS, 2012).

É razoável pensar que, na medida em que as instituições mantenham, no decorrer do tempo, a característica de atender às expectativas dos indivíduos, a socialização venha a reforçar os efeitos positivos do desempenho institucional satisfatório. Inclusive, isso se traduziria em um problema para as democracias recentes. A população apresenta muita desconfiança quanto às instituições do regime militar brasileiro, principalmente as polícias, ao mesmo tempo em que as organizações em fase de estruturação ainda não são capazes de atender adequadamente às expectativas geradas a partir do período de transição, como, por exemplo, aquelas referentes ao respeito aos direitos humanos e às liberdades individuais (OLIVEIRA, 2011, p. 10).

A história do controle social no Brasil e em muitos países é marcada pela marginalização de grupos sociais desprivilegiados (Coelho, 1978; MISSE, 2007; PAIXÃo, 1990; SILVA, 2011). No início do 
período republicano, predominavam ideais positivistas e eugênicos com a busca do controle por meio do higienismo social (BASTOS NeTO, 2006; SILVA, 2011; STANCIK, 2006). É elucidativo, neste período, que os principais motivos de aprisionamento fossem a vadiagem (caracterizada pelo fato de não se trabalhar, mesmo que não houvesse vagas disponíveis) e a embriaguez (ZALUAR, 1996).

Adorno (1994), Belli (2004), Costa (2004b), Krok (2008), Mesquita Neto (1999) e Pinheiro (1997), ao tratarem do Brasil, consideram a polícia militarizada e repressiva, além de altamente seletiva. Grande parte dessas características é explicada pelos autores através da herança do governo militar e da influência do exército na constituição da polícia brasileira, o que continua se reproduzindo pela tradição e estrutura política existente:

\footnotetext{
"A vigência efetiva dessas condições distingue o Estado democrático do Estado autoritário, também conhecido como Estado policial em razão dos graus elevados de liberdade das agências de repressão [...] Apenas recentemente a sociedade brasileira se apercebeu das articulações positivas entre polícia e cidadania. [...] A autonomia das instituições legais e sua capacidade efetiva de afetar processos e comportamentos organizacionais e individuais têm peso historicamente significativo na garantia dos direitos de cidadania nas operações das agências públicas de controle social" (PAIXÃo \& BEATO, 1997, p. 233.234; 237).
}

Pode-se afirmar que há dificuldade de realização da cidadania no Estado democrático devido à persistência de vieses e transgressão de direitos. Essa conjuntura é favorecida pelas características organizacionais da polícia, que, na autonomia que the é ofertada com o objetivo de dificultar instrumentalizações políticas, conferem-Ihe discricionariedade. Não há consenso quanto a um modelo de instituição policial ideal, mas um grande debate sobre o tema expressando a insatisfação pública, tanto com os índices de violência como com os recursos utilizados na sua contensão.

Pela perspectiva de Goldstein (2003), a baixa confiança na polícia resulta da associação equivocada entre a função policial e a função do sistema de justiça criminal como um todo. Para Bowling \& Foster (2002), por sua vez, considerar que a polícia tem relacionamento harmonioso com a comunidade é um mito. Isso por haver padrões de policiamento diferenciados segundo classe, gênero, idade e etnicidade. Daí a importância de variáveis sócio-demográficas serem inseridas como explicativas da confiança na polícia. Considerando que há diferença de tratamento da polícia a grupos sociais distintos, importa identificar o efeito disso no nível de confiança que recebe.

Temos, portanto, duas perspectivas distintas, mas não excludentes, quais sejam: por um lado, a polícia, favorecida por características organizacionais e históricas, atua de forma seletiva ao praticar coerção, mas, por outro, está entre as instituições estatais mais presentes, atuando de forma assistencialista em áreas carentes. De alguma maneira, estas características influenciam o seu nível de confiança, seja negativamente, quando ela não consegue manter a ordem ou usa da violência na tentativa de fazê-lo, seja positivamente, quando a polícia assiste à população com procedimentos justos ou é tida como eficiente. 
SILVA, G. F.; BEATO, C. Confiança na polícia em Minas Gerais: o efeito da percepção...

\section{Possíveis determinantes da confiança na polícia}

Buscou-se, a partir da bibliografia sobre o tema, identificar quais são os principais fatores que influenciam a confiança na polícia e de que modo se dá essa influência. Para uma maior coesão do artigo, optamos por enfocar naqueles que teríamos condições de testar a partir dos dados disponíveis. Poderíamos agrupar os fatores aqui considerados em: socioeconômicos; contato com a instituição e percepção de eficiência. Dada a opção por enfocar os fatores possíveis de serem testados com os dados de que dispomos, não dedicamos grande atenção a outras influências que se deve ter consciência da relevância, como, por exemplo, a cultura.

Todos os estudos empíricos utilizados neste artigo levam em conta características socioeconômicas e/ou demográficas para explicar a variação no nível de confiança na polícia em nível individual. As mais recorrentes são sexo, idade, raça/cor, escolaridade, renda, estado civil e religião (BRoWn \& BENEDICT, 2002; WeITZER \& TUCH, 2004, p. 307). Também são tidas como variáveis relevantes na explicação dessa confiança o contato dos cidadãos com a polícia e a percepção da eficiência do seu trabalho, principalmente no combate ao crime. Na sequência, apresentamos as premissas sobre cada uma delas:

Idade

Uma das variáveis mais exploradas e com impacto mais consistente na percepção da polícia é a idade (BRown \& BENEDICT, 2002; SANTOS, 2010). Quanto mais anos de vida possui o indivíduo maior a sua tendência em confiar na polícia (MYHILL \& BEAK, 2008). Logo, adultos têm percepção mais favorável da polícia do que os jovens e os idosos tendem a confiar mais e reportar maior proporção de crimes (HURST et al, 2000; SKOGAN, 1984). Mesmo em outras instituições como o parlamento, em diversos países, os resultados convergem (MAGALHÃES, 2003, p. 460).

No Brasil, enquanto Lopes (2010), utilizando dados do Latinobarômetro, não encontrou efeito estatisticamente significativo, Oliveira (2011), com dados do IPEA, obteve resultado concordante com a maioria das pesquisas. Mesmo quando não se trata do nível individual, a idade influencia a confiança. Cidades com menor proporção de jovens possuem maior tendência de confiança elevada (HURST et al, 2000).

Conforme Bittner (2003), jovens possuem natureza isenta de preocupações e seriedades, o que os torna mais inclinados à má conduta. $\mathrm{O}$ fato de os chamados distúrbios juvenis ocorrerem em lugares públicos faz a polícia levar em consideração a preservação desses espaços. Policiais são sensíveis a provocações e tomam como tal comportamentos sutis e desejam estar em vantagens táticas. Essa configuração favorece o conflito entre policiais e jovens.

\section{Escolaridade}

Anos de estudo também produzem efeitos consideravelmente consistentes no nível de confiança na polícia, entretanto, o impacto é negativo. Quanto mais anos de estudo o indivíduo tem, menor tende a ser sua confiança (BROWN \& BENEDICT, 2002, p. 554; 551; OLIVEIRA, 2011, p. 12; 16).

Colegiais, por exemplo, são mais satisfeitos do que universitários, que, por sua vez, acham a polícia mais agressiva. Paixão e Beato estranham o fato de os mais estudados recorrerem menos à polícia e relacionam esse fato à descrença e à desconfiança: 
"É interessante notarmos como a desconfiança e o descrédito daqueles que não acreditavam na polícia, e por isso não a procuraram, se dá entre as pessoas que são mais educadas numa proporção duas vezes maior do que entre aqueles que tinham menos de 4 anos de estudo. Seria de se esperar que essa cultura cívica (traduzida em algum grau na confiança nas instituições de mediação e dissuasão de conflitos) fosse maior entre as pessoas mais educadas, o que não ocorre" (PAIXÃo e BEATO, 1997, p. 242).

Ao contrário do que poderia ser mais intuitivo, anos a mais de estudo provocam maior sentimento de ilegitimidade ou ineficácia quanto à polícia. Ao estudar mais, o indivíduo passa a ser mais crítico à sua atuação. Porém, há que destacar que Frank et al (2005), que estudam a polícia americana, encontram que o aumento da educação produz efeitos positivos nos níveis de confiança e satisfação.

Renda

A variável renda produz efeitos ainda mais adversos. No Brasil, Oliveira (2011) não encontra resultados estatisticamente significativos e Lopes (2010) não inclui a variável na sua análise empírica. De acordo com Macdonald et al (2007, p. 26), o status socioeconômico está associado à percepção de tratamento desleal e injusto. Indivíduos com status socioeconômico alto são mais propensos a considerar que a polícia trata as pessoas com deslealdade e injustiça, o que está de acordo com Weitzer \& Tuch (2004). De acordo com Brown \& Benedict (2002, p. 551), vários pesquisadores têm encontrado que ter baixa renda favorece uma visão favorável da polícia. Avdija (2010, p. 78), entretanto, verificou que baixo status socioeconômico revela atitudes negativas.

Cor/etnia

Em geral, a confiança na polícia é baixa especialmente quando se trata de indivíduos pertencentes a grupos minoritários (TYLER, 2005). Há um histórico estranhamento entre polícia e as populações pobres, o que pode fazer com que um incidente crítico produza efeitos negativos (BROWN \& BENEDICT, 2002, p. 544). Há alta disponibilidade de papers que enfocam as diferenças da confiança policial de acordo com a etnia/cor. Os estudos são quase unânimes em afirmar que os negros têm menos atitudes favoráveis (HURST et al, 2000) ou confiam menos do que os brancos, o que é predominantemente explicado pela teoria do conflito (MACDONALD et al, 2007, p. 30).

De acordo com Brown \& Benedict (2002), que revisaram mais de 100 artigos sobre atitudes em relação à polícia, o aspecto desse tema mais estudado é sua relação com minorias e os negros, apontando que estes tendem a ter uma visão negativa. Grande parte dos estudos encontram que a raça é o principal preditor da percepção sobre a polícia. Nos Estados Unidos, a maioria dos negros são críticos ao policiamento.

A confiança e a percepção sobre a polícia seguem, dessa forma, uma escala de cor da pele. Os negros possuem menores confiança e satisfação com a polícia (BROWN \& BENEDICT, 2002; FAGAN, 2008, p. 123; Frank et al, 2005; HOWELL, 2004; BROWN \& BenEDICT, 2002; SANTOS, 2010; TAXMAn et al, 2005; TYLER, 2005) e percebem maior discriminação. Já os brancos acreditam na imparcialidade policial (WEITZER \& TUCH, 2004). 
SILVA, G. F.; BEATO, C. Confiança na polícia em Minas Gerais: o efeito da percepção...

Para Brunson \& Miller (2006), o menor apoio dos negros à polícia deve-se à desproporcionalidade da ação desta de acordo com a cor; já para Brown \& Benedict (2002, p. 548), a avaliação negativa da polícia por negros é fomentada pelo contato negativo com ela. Enquanto os grupos dominantes perceberiam a polícia como aliada e teriam medo de perder os privilégios, os grupos minoritários tendem a perceber mais abusos e fornecimento de serviços insuficientes, o que favorece o menor nível de confiança (CAO, 2011, p. 3-4).

A etnicidade é consistentemente associada à confiança nos Estados Unidos, Inglaterra, Gales, onde os negros tendem a ter visão negativa da polícia (MYHILL \& BEAK, 2008). O mesmo ocorre no Reino Unido. Entretanto, há diferentes resultados entre as pesquisas realizadas nas mesmas e em diferentes regiões (BROWN \& BENEDICT, 2002). Por exemplo, Frank et al (2005, p. 222), não encontraram significância estatística para o efeito da raça sobre o comportamento dos cidadãos em relação à polícia. O mesmo começa a ocorrer no Brasil. Apesar de contarmos com apenas dois estudos, Oliveira (2011, p.18) encontrou que ser "não branco" reduz a confiança na polícia enquanto Lopes (2010, p. 19) não obteve significância estatística para a variável cor em sua associação com a confiança na polícia.

Sexo

Quanto ao sexo, de acordo com Cao (2011, p. 18), pessoas do sexo feminino são mais propícias a expressar confiança na polícia do que as do sexo masculino. 0 mesmo é apontado por Hudson (2006, p. 57). Isso sugere que as mulheres são mais suscetíveis a atender a requisições da polícia, além de possuírem menor tendência de se envolverem em situações que a polícia venha a agir contra elas.

Avdija (2010, p. 85) reconhece que, na literatura predominante, as mulheres tendem a avaliar a polícia mais positivamente do que os homens, mas, em seu estudo, obtém resultado inverso. Segundo Brown \& Benedict (2002, p. 554), não há consenso sobre os efeitos do gênero sobre as atitudes em relação à polícia. Enquanto Magalhães (2003, p. 460) não obtém índices estatisticamente significativos para a influência do gênero na confiança no parlamento em vários países, Moisés (2008, p. 26; 40) encontra que ser do sexo masculino é estatisticamente significativo e reduz a crença na democracia na América Latina e aumenta a desconfiança.

Apesar de os resultados das pesquisas já realizadas não produzirem consenso quanto ao impacto do estado civil na confiança, espera-se que os casados sejam mais propensos a confiar na polícia, pois, tal como os mais velhos, são menos percebidos como suspeitos e têm menos embates com a polícia. Isso é confirmado por Macdonald et al (2007, p. 26), que encontra que indivíduos casados são menos prováveis de serem críticos às práticas policiais. Por sua vez, Cao (2011, p. 13) afirma que o fato de ser casado favorece o nível de confiança individual.

Religião

Apesar de menos estudada, a religião é também considerada um aspecto importante para explicar a confiança nas instituições. O pertencimento a grupos religiosos, bem como a outras comunidades ou grupos com relações face a face, induz os participantes a assimilarem normas de cooperação e de reciprocidade que funcionam como elementos de contenção dos riscos de abuso de confiança (Moısés, 2005). 


\section{Contato direto/indireto}

Além das variáveis sociodemográficas, a confiança também é baseada nas experiências do indivíduo com a instituição policial. Essas experiências podem ser diretas (pessoais) ou indiretas, por meio da informação de outras pessoas (vicárias) ou da mídia. De acordo com Brown \& Benedict (2002, p. 547), estudos têm indicado que a variação do apoio à polícia segundo grupos demográficos é afetada pelas influências que os tipos de contato provocam na percepção sobre ela.

Os diferentes tamanhos de cidade, com formas de organização próprias possuem sociabilidades diferentes, portanto, formas de contato específicas mesmo entre os indivíduos, e relações diferenciadas com as instituições (SIMMEL, 1987). Em estudos sobre distribuição dos crimes violentos, são identificados padrões de acordo com esses tipos de cidade, o que pode interferir na relação polícia/público (BEATO, 1998; 2010).

Enquanto alguns formulam a opinião sobre a polícia a partir de percepções gerais, outros o fazem pela observação de comportamentos específicos. Assim, a proximidade das agências pode influenciar a atitude e sentimento dos cidadãos (FRANK et al, 2005). A proximidade seria naturalmente estabelecida em pequenas localidades ou de costumes tradicionalistas. Torna-se relevante verificar a hipótese de que, nas cidades pequenas, regiões e estados tradicionais, há maior confiança na polícia em função da coesão local, nível de crime, e do tipo de contato estabelecido.

De acordo com Hudson (2006), o contato com a polícia é estabelecido de maneira direta ou indireta. O contato indireto é, na realidade, conhecimento ou informação. Pode se dar através da mídia ou de informações de terceiros. Já o contato direto é pessoal com a instituição ou algum seu representante. As características da instituição policial permitem que haja os dois tipos de contato.

É importante considerar que o grau de confiança que o indivíduo possui é afetado pelos acontecimentos que já ocorreram em sua vida. Os chamados antecedentes da confiança são tidos como essenciais. Por isso, aspectos como violência e corrupção são importantes, mas a confiança também depende do histórico de confiabilidade e efetividade da instituição. Ao entrar em contato, leva-se em conta o que há de registro na memória ou história. Apresenta-se uma reação subjetiva que pode ser acionada na consciência coletiva. Por outro lado, a experiência cotidiana pode reforçar as impressões da coletividade ou endossar as interações sociais, o que nesse caso interfere na eficiência policial (TANKEBE, 2010, p. 297-299).

Entretanto, o mais óbvio impacto (positivo ou negativo) do contato direto com a polícia sobre a confiança nela depende da avaliação que o indivíduo faz do encontro que teve com os agentes. Quando a avaliação é positiva o impacto na confiança tende a ser positivo (CAO, 2011, p. 06). Pesquisas têm encontrado que quanto maior é o contato dos cidadãos com os policiais, menor tende a ser a satisfação com sua performance. E, quando indivíduos já passaram por experiências de corrupção ou brutalidade policial, tendem a fazer uma pior avaliação da instituição (AVDIJA, 2010, p. 77; BROWN \& BENEDICT, 2002 , p. 551-552; CAO, 2011, p. 06; HERRMANN et al, 2011; TANKEBE, 2010, p. 296; TAXMAN et al, 2005).

A confiança é construída coletivamente com base no julgamento sobre o cumprimento da função institucional. É composta por crenças e expectativas, e não somente por observação e conclusões originárias de experiências pessoais. Embasa-se na avaliação que o público faz da instituição através do contato pessoal, mas também indiretamente pela mídia. Para além da ação de indivíduos e 
SILVA, G. F.; BEATO, C. Confiança na polícia em Minas Gerais: o efeito da percepção...

instituição, a confiança depende da interpretação feita por cidadãos e terceiros (Kä̈̈RIÄINEN, 2008, p. 143).

O grau de conhecimento sobre a instituição pode influenciar o nível de confiança. A mídia tem maior poder de influenciá-lo no caso do sistema de justiça e polícia pelo fato de que pequena parcela da população tem experiência direta com essas instituições. A proporção de pessoas que entram em contato direto com o sistema de saúde, por exemplo, é muito maior (RoBeRTs, 2007, p. 162). Como a proporção de indivíduos que têm contato direto com a polícia é baixa, a maioria das pessoas pauta sua percepção através da experiência de outras, o que é acessado por conversas informais e meios de comunicação (WEITZER \& TUCH, 2004, p. 308).

Dentre algumas abordagens sobre mídia, com frequência, a imprensa é inserida numa relação de poder, que favorece ou prejudica a legitimidade de ações de determinadas instituições como a polícia. A mídia pode legitimar a ação policial e, ao mesmo tempo, o abuso de poder e a autoridade policial através do apoio a ações ilegais. O posicionamento da mídia influencia a opinião pública tanto para o apoio a ilegalidades como pode levar à percepção de que a instituição não é eficiente (WooD, 2010).

Do lado da instituição policial, a relação entre polícia e mídia exerce a função de contribuir com a comunicação da polícia com o público. As notícias "de lei e ordem" são frequentes e seguiriam a tendência de favorecer a polícia, transmitindo visão positiva da instituição. Porém, isso pode se tornar risco para a sociedade por poder legitimar autoritarismo e violência policial (MAWBY, 2010).

Os meios de comunicação desempenham papel importante na percepção do público em relação à violência e à aceitação do processo penal. Por suposto combate ao crime, ações ilegais e mesmo guerras seriam legitimadas. Os contextos culturais de comunicação de massa que promoveriam o medo do crime, por um lado, justificariam ilegalidades do Estado ao "combatê-Io" (ALTHEIDE, 2006).

O crime seria reproduzido nos meios de comunicação como espetáculo para o público. Relações de poder explicariam, ao menos em parte, a exposição de crimes na mídia, utilizada como instrumento de dominação ao contribuir para a legitimação de dominantes e a situação desprivilegiada de dominados (SUPER, 2010).

Por outro lado, é possível que a mídia transmita uma imagem de ineficiência da polícia ao publicar eventos criminais, explorando principalmente os mais violentos. Os cinco principais jornais da imprensa escrita mineira, por exemplo, publicaram em 29 edições de janeiro de 2009, 822 matérias sobre crime. A maior parte $(31,6 \%)$ dos crimes publicados foi homicídio. Ainda, 9,3\% foram crimes de violência sexual. Tais tipos de crimes não ocorrem em proporção tão elevada, mas, do mesmo modo que a população registra os crimes mais graves, a imprensa tende a publicar mais frequentemente os mais violentos (SILVA \& BRAGA, 2012).

Apesar da alta exposição de crimes na mídia, isso não inviabiliza que ela favoreça a polícia, já que a imprensa depende das informações policiais para esse tipo de publicação. Dessas matérias, em 79,2\% a polícia serviu de fonte, na maioria das vezes única. Em 96,8\% dessas matérias não houve apresentação de opiniões divergentes. Logo, pode haver uma tendência de que a imprensa, ao publicar crimes, transmita a mensagem de forma a favorecer a polícia (SILVA \& BRAGA, 2012). 
Muniz (1999) apresenta a potencialidade ambígua da mídia em favorecer e prejudicar a percepção que os indivíduos têm sobre a polícia. Por um lado, tem-se uma visão heroica: "Estamos, de alguma forma, em contato com elas: através da idealização heroica e quase sempre romântica dos seriados de TV, dos trillers de ação e dos folhetins policiais; nos noticiários sobre crimes e violência policial" (MuNız, 1999, p. 41). Mas por outro, é possível que haja demonização:

\footnotetext{
"A demonização dos meios de comunicação de massa, particularmente a televisão, tem sido uma moeda corrente nas queixosas narrativas policiais. Segundo esses discursos, as TVs estariam diariamente divulgando os maus hábitos, elogiando os péssimos exemplos de comportamento e, por conta disso, promovendo não só a 'banalização da violência' como também uma 'destrutiva inversão dos valores da sociedade'” (MuNIZ, 1999, p. 41).
}

Se a mídia repercute comportamentos condenáveis da polícia, o seu prestígio e confiança são gravemente afetados. Quando oficiais da Filadélfia admitiram terem obtido confissões por meio de coerção em vizinhanças pobres, falsificado evidências e praticado perjúrio em mais de 1500 casos, principalmente com negros, houve intensificação da cobertura da imprensa. A percepção da polícia se negativou e muitos passaram a enxergá-la como gangue (BROWN \& BENEDICT, 2002, p. 545).

Estar exposto aos registros da má conduta policial na mídia aumenta a percepção de que a polícia se comporta mal. Reality shows sobre polícia tendem a favorecer a percepção positiva sobre ela, enquanto a cobertura de abusos prejudica. Um único incidente pode causar grande impacto na opinião pública. Cada acontecimento conhecido pode ser internalizado e até mesmo experimentado vicariamente. Ou seja, um indivíduo pode comunicar sua experiência com a polícia para amigos, família, conhecidos e vizinhos com a possibilidade de propagar suas crenças (MYHILL \& BEAK, 2008, p. 10; WEITZER \& TUCH, 2004, p. 308).

\section{Contato voluntário/compulsório}

Também é importante levar em conta se o contato com a polícia é voluntário ou compulsório. Assim, é importante saber se o contato foi iniciado pela polícia ou pelo cidadão. Se os indivíduos são mais preocupados com os procedimentos do que com os resultados, o contato compulsório com a polícia oferece maior probabilidade de reduzir a confiança (AVDIJA, 2010, p. 79; BROWN \& BENEDICT, 2002; KÄÄRIÄINEN, 2008; KÄÄRIÄINEN \& SIRÉN, 2011; MYHILL \& BEAK, 2008, p. 05).

"Quando é o cidadão quem inicia o contato com a polícia, há maior predisposição em avaliá-la positivamente do que quando a polícia inicia o contato" (BROWN \& BENEDICT, 2002, p. 552). É provável que haja, inclusive, confusão entre a avaliação do contato com a percepção dos serviços prestados. Quando o contato é iniciado pelo cidadão, há maior chance de que o mesmo seja considerado satisfatório. Entretanto, quando o encontro é avaliado como satisfatório nos dois tipos de contato direto, geralmente tem-se uma avaliação positiva. Quando o contato é considerado insatisfatório, independente de quem o iniciou, avalia-se negativamente a instituição (MYHILL \& BEAK, 2008, p. 18).

Apesar de alguma divergência sobre os efeitos do contato iniciado pela polícia, a avaliação negativa é mais frequente entre cidadãos que foram pessoalmente parados por ela, por exemplo. Indivíduos que já foram presos a avaliam mais negativamente do que os demais. Pessoas que já foram 
SILVA, G. F.; BEATO, C. Confiança na polícia em Minas Gerais: o efeito da percepção...

advertidas ou receberam multas no trânsito também expressam menor confiança (BROWN \& BENEDICT, 2002, p. 552; CAO, 2011, p. 06). Quando o indivíduo tem um passado de práticas e atos ilegais também está menos propenso em acioná.la e a desconfiá.la (SKOGAN, 1984).

Jovens compreendem uma significante parcela da população que se encontra presa, tendo entrado em contato com a polícia para esta prisão. A idade também influencia o contato, o que, por sua vez, impacta a confiança (CAO, 2011, p. 08; HURST et al, 2000). A polícia mantém frequentemente contato com pessoas de pouca idade principalmente para promover a manutenção da ordem. Isso faz com que haja conflito provocando impressão negativa (HURST et al, 2000, p. 40. 41).

A avaliação que é feita pelo público leva em conta aspectos ideológicos e relaciona-se com a opinião ou ênfase que se dá à punição e ao comportamento da instituição. Outras instituições são avaliadas mais pragmaticamente e menos ideologicamente do que as que estão atreladas ao sistema de justiça. A cultura é de grande importância, porém, não anula o contato direto, apesar de que experiências anteriores possam ser importantes (ROBERTS, 2007, p. 165).

\section{Percepção de eficiência}

A percepção acerca do desempenho das instituições guarda alta correlação com a confiança que as mesmas recebem. Quanto mais se considerar a instituição eficiente no cumprimento de sua função, maior tendência de se confiar nela (GOLDSMITH, 2005; HUDSON, 2006; KOURY, 2002; MAGALHÃES, 2003; MoIsÉs, 2005; 2008; OLIVEIRA, 2011; ROTHSTEIn, USLANER, 2005; StOUTLAND, 2001).

Como proposto por Goldstein (2003), a percepção da polícia é influenciada pela sua associação ao sistema de justiça criminal. Ainda que a maior parte das atividades policiais não esteja relacionada à contenção da criminalidade, essa é tida como a sua principal função. Em geral, essa é a visão do público e de policiais corroborada pelos meios de comunicação. Portanto, considera-se a polícia eficiente se ela controla o crime, e quando é vista como eficiente no cumprimento desta função ela recebe ainda mais confiança.

A vitimização vicária e direta, tal como a sensação de insegurança e a percepção sobre o aumento do crime, reduz o grau de confiança que a instituição policial recebe (BROWN \& BENEDICT, 2002; CAO, 2011, p. 06; HeRrmann et al, 2011; HuRSt et al, 2000; 2005; Howell, 2004; MyHILL \& BeAK, 2008; Oliveira, 2011, p. 19; PAixÃo \& BeAto, 1997, p. 233; RoberTs, 2007; Tyler, 2005).

Quem foi vítima, ou tem mais medo de ser, tende a avaliar a polícia mais negativamente. A ocorrência de crime e vitimização estão entre as características mais consistentes enquanto capazes de reduzir o nível de confiança policial. Podem, inclusive, produzir efeitos mais fortes do que as variáveis demográficas (BRown \& BENEDICT, 2002). Perceber que o crime é um problema sério reduz o nível de confiança na polícia. Observações empíricas indicam existir associação da desconfiança com a experiência de insegurança:

“Nos Estados Unidos e no Reino Unido, por exemplo, pode ocorrer isto. Em países onde os problemas de crime são experimentados comograves, a polícia está provavelmente confrontada mais com as expectativas do combate ao crime do que em países onde a criminalidade é vivida como um problema social relativamente pequeno. $\mathrm{Na}$ Finlândia, muitas outras questões sociais além do crime são colocadas em discussão de 
políticas públicas [...] o crime ocupa uma posição marginal no debate político"

(KÄ̈̈RIÄINEN, 2008, p. 155).

Para Oliveira (2011), a percepção da eficiência do trabalho policial é central para explicar a confiança na polícia. Usando dados da pesquisa do IPEA referente ao Brasil, tem-se que o grau de confiança é precedido da avaliação do trabalho da polícia. Assim, a opinião pública exerce papel importante, pois cidadãos não satisfeitos tendem a não confiar e não acionar a instituição.

\section{Metodologia}

Como base empírica para este artigo, foram utilizados os dados do survey da pesquisa de “Vitimização e Percepção de Medo em Belo Horizonte e Minas Gerais", realizado pelo CRISP em 2009. Salientamos que nosso objetivo não está diretamente relacionado com o da pesquisa, entretanto, dentre as bases que acessamos, é a que melhor o contempla. Tem-se como unidade de análise o indivíduo no domicílio, de acordo com o plano amostral da pesquisa realizada no ano 2008 e replicada no ano seguinte com a seguinte distribuição:

Tabela 1

Distribuição das entrevistas

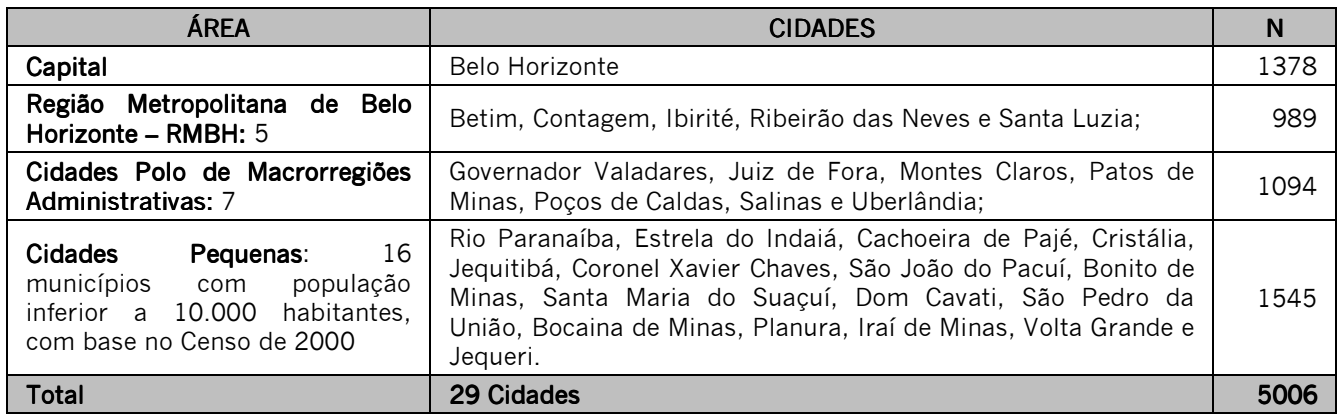

Fonte: CRISP / UFMG, 2009.

Foram realizadas entrevistas em 29 municípios mineiros. Além da capital, 5 cidades da RMBH, as 7 cidades do polo regional e 16 municípios pequenos (população inferior a 10 mil habitantes) de cada uma das 8 macrorregiões administrativas. A pesquisa teve amostragem intencional quanto às cidades, mas contou com sorteio dos setores censitários, domicílios e entrevistados de acordo com princípios probabilísticos, garantindo aleatoriedade em todos os níveis.

Como tratou-se também de uma pesquisa de vitimização, questões relativas à confiança nas instituições foram inseridas no questionário, a fim de possibilitar o teste do impacto da vitimização na confiança, especialmente nas instituições responsáveis pela segurança pública como governos, justiça e polícia.

A variável dependente, confiança na polícia, foi construída a partir da questão: "Por favor, gostaríamos que o Sr. (a) dissesse o quanto confia em cada uma das seguintes instituições listadas a seguir:". Além da Polícia o entrevistado deveria também dizer o quanto confia no Poder Judiciário, Igreja, Imprensa, Governo Municipal, Governo Estadual e Governo Federal de acordo com uma escala de 0 a 10 em que 0 significa confiar nem um pouco e 10 significa confiar muito ou totalmente. 
SILVA, G. F.; BEATO, C. Confiança na polícia em Minas Gerais: o efeito da percepção...

Para empreender uma análise descritiva das variáveis pertinentes ao estudo, a variável confiança na polícia foi recategorizada. Considerou-se 0 como Nenhuma confiança, de 1 a 4 como Baixa, de 5 a 8 Média e 9 e 10 Alta. A análise descritiva é importante para indicar as tendências de comportamento dos indivíduos segundo agrupamentos, ou seja, para sugerir padrões. Entretanto, para isolar os efeitos das variáveis, é necessário realizar uma análise de regressão. Para aplicação da regressão linear, a variável foi mantida na forma original, portanto, com a escala ordinal. Para que o modelo de regressão linear possa ser aplicado é necessário que a variável tenha distribuição normal, o que é atestado pelo histograma (Gráfico 1 ):

\section{Gráfico 1}

Histograma da variável dependente

Confiança na Polícia

(Escala de 0 a 10)

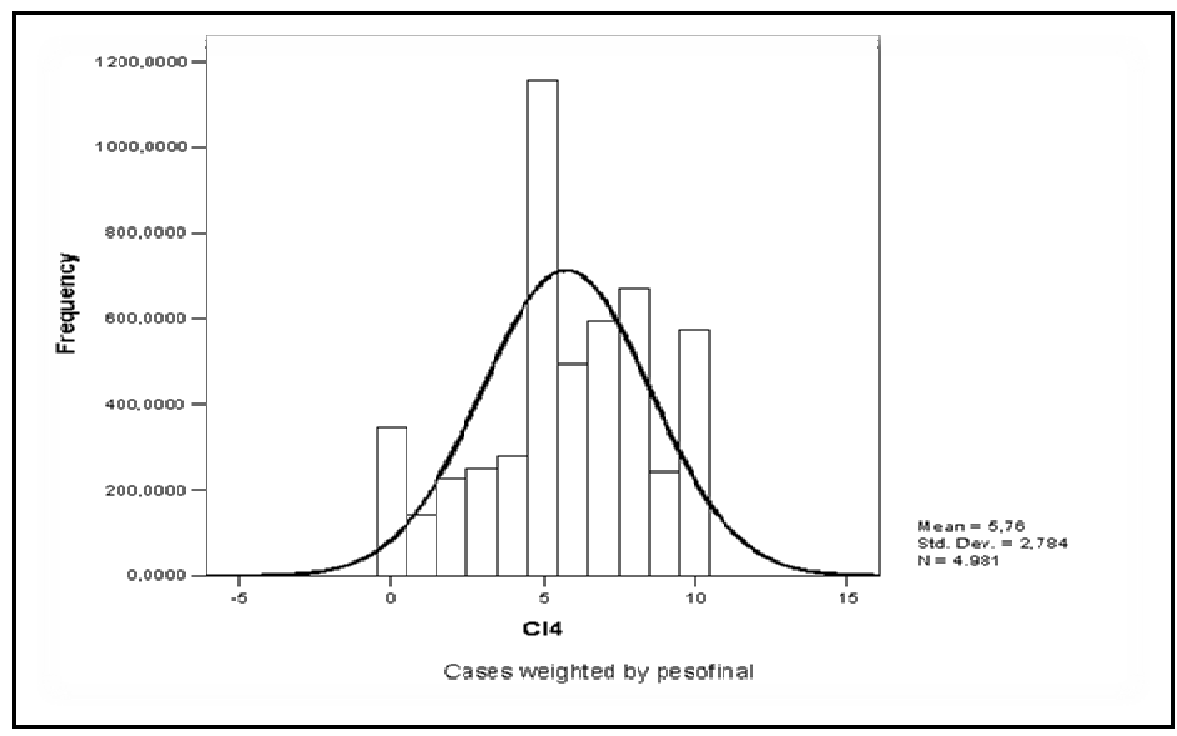

Apesar de o histograma não seguir perfeitamente a curva da normal, há uma concentração dos resultados em torno da média, sendo assim, a variável dependente, confiança na polícia, em escala de 0 a 10, possui distribuição aproximadamente normal, podendo ser submetida ao modelo de regressão linear. A curtose do gráfico, ou seu formato quanto ao achatamento e afunilamento é mesocúrtico, ou seja, tende para o centro (DANCEY, 2006, p. 89; 95). A curva é consideravelmente simétrica, tem pico único e se apresenta com um formato de sino, características da distribuição normal (MoORE, 2000, p. 43).

A Tabela 2 apresenta as estatísticas descritivas da variável dependente: 
Tabela 2

Estatísticas Descritivas da Confiança na Polícia

(Escala de 0 a 10)

\begin{tabular}{|c|c|c|c|c|c|}
\hline & N & Mínimo & Máximo & Média & $\begin{array}{c}\text { Desvio } \\
\text { Padrão }\end{array}$ \\
\hline Confiança na polícia (escala de 0 a 10) & 4981 & 0 & 10 & 5,76 & 2,784 \\
\hline Valid N (listwise) & 4981 & & & & \\
\hline
\end{tabular}

Variáveis independentes

As variáveis explicativas da confiança na polícia são o sexo, idade, escolaridade, renda, estado civil, raça/cor, religião, os contatos direto e indireto com a polícia, a percepção de sua eficiência e o tipo de cidade do entrevistado (Tabela 3).

A variável idade é contínua. As variáveis sexo, estado civil, raça/cor e religião são dicotômicas. Tomaram-se como categorias indicadoras: ser masculino na variável sexo, casado no estado civil, branco em raça/cor e ter qualquer religião na variável religião. As variáveis escolaridade e renda foram dicotomizadas a partir dos percentis do cruzamento com a confiança na polícia. Os valores que se enquadravam a partir do sexto percentil foram nomeados como indicadores: para a escolaridade, ter a partir do Ensino Médio incompleto e, para a renda, ganhar mais de 2 salários mínimos.

Classificou-se o contato direto com a polícia em voluntário, quando o indivíduo toma iniciativa de entrar em contato, e compulsório, quando o indivíduo não tem como optar por não entrar em contato com a polícia. Utilizaram-se as variáveis obtidas da seguinte questão: "Nos últimos cinco anos, você teve contato com a polícia em alguma das seguintes situações?". Para o contato voluntário, temos: 1) Solicitou informações a um policial; 2) Procurou a polícia por ser vítima de um crime; 3) Procurou a polícia para avisar sobre um acidente de trânsito; 4) Informou-se sobre crime com um policial. Para o contato compulsório, temos: 1) Foi revistado; 2) Teve contato com a polícia para resolver algum conflito entre vizinhos ou amigos; 3) Foi abordado por policiais que estavam investigando um crime; 4) Foi parado numa blitz policial. Em todas as variáveis, as categorias de resposta são: 1- Sim e 0. Não.

Para mensurar o contato indireto, a questão utilizada é a seguinte: "Como você fica informado sobre criminalidade e violência em sua cidade?" 1) Através da Televisão; 2) Através de rádio; 3) Através de jornais impressos; 4) Através de conhecidos, parentes, amigos e vizinhos; 5) Através da Internet. As categorias de resposta são: 1 - Sim e 0. Não.

Mensuramos a percepção da eficiência da polícia a partir dos dados resultantes da questão: "Na resolução de problemas de violência na sua cidade, você diria que a Polícia ê": 1) Muito eficiente; 2) Razoavelmente eficiente; 3) Pouco eficiente; 4) Nada eficiente. As duas primeiras categorias de resposta foram agrupadas como 1 . "Tende a perceber a polícia como eficiente" e as categorias 3 e 4 como 0 "Tende a perceber como ineficiente".

$\mathrm{O}$ efeito do tipo de cidade é mensurado pelas categorias: ser da $\mathrm{RMBH}$, de cidade polo ou ser de cidade pequena. Para cada categoria foi gerada uma variável em que ser do tipo da cidade $(\mathrm{RMBH}$, cidade polo ou cidade pequena) é igual a 1 e as demais igual a 0. 
SILVA, G. F.; BEATO, C. Confiança na polícia em Minas Gerais: o efeito da percepção...

Tabela 3

Estatísticas descritivas das

variáveis independentes

\begin{tabular}{|c|c|c|c|c|c|}
\hline Variáveis independentes & \multirow{2}{*}{$\mathrm{N}$} & \multirow{2}{*}{ Mínimo } & \multirow{2}{*}{ Máximo } & \multirow{2}{*}{ Média } & \multirow{2}{*}{ Desvio Padrão } \\
\hline Socioeconômicas & & & & & \\
\hline Sexo (Masculino=1) & 5005 &, 00 & 1,00 & ,4556 & ,49807 \\
\hline Idade & 5005 & 14 & 99 & 39,31 & 16,655 \\
\hline Estado civil (Casado $=1)$ & 5005 &, 00 & 1,00 & ,4177 & ,49323 \\
\hline Branco/Não Branco $($ Branco=1) & 5005 &, 00 & 1,00 & ,4188 & ,49341 \\
\hline Ter religião & 5002 &, 00 & 1,00 & ,8935 & ,30853 \\
\hline Até $8^{\mathrm{a}}$ Série $/+$ que $8^{\mathrm{a}}$ Série $\left(+\right.$ que $8^{\mathrm{a}}$ Série $=1$ ) & 4995 &, 00 & 1,00 &, 5063 &, 50001 \\
\hline Até $2 \mathrm{SM} /$ Mais de $2 \mathrm{SM}$ (Mais de 2 Salários Mínimos=1) & 4932 &, 00 & 1,00 & ,4938 &, 50001 \\
\hline \multicolumn{6}{|l|}{ Contato direto com a polícia - voluntário } \\
\hline Solicitou Informações & 5005 &, 00 & 1,00 & 1,75 & ,436 \\
\hline Procurou por ser vítima de crime & 5005 &, 00 & 1,00 & 1,79 & ,407 \\
\hline Procurou para avisar sobre acidente de trânsito & 5005 &, 00 & 1,00 & 1,92 & ,267 \\
\hline Informou-se sobre crime por policiais & 5005 &, 00 & 1,00 & 1,97 &, 180 \\
\hline \multicolumn{6}{|l|}{ Contato direto - Compulsório } \\
\hline Foi Revistado & 5005 &, 00 & 1,00 & 1,86 & ,350 \\
\hline $\begin{array}{c}\text { Teve contato para resolver conflito entre } \\
\text { vizinhos/amigos }\end{array}$ & 5005 &, 00 & 1,00 & 1,89 & ,311 \\
\hline Foi abordado em investigação de crime & 5004 &, 00 & 1,00 & 1,94 & ,232 \\
\hline Foi parado numa Blitz & 4977 &, 00 & 1,00 & 1,80 & ,398 \\
\hline \multicolumn{6}{|l|}{ Contato indireto/informou sobre crime por... } \\
\hline Televisão & 5005 &, 00 & 1,00 & 1,35 & ,478 \\
\hline Rádio & 5005 &, 00 & 1,00 & 1,73 & ,446 \\
\hline Jornais impressos & 5005 &, 00 & 1,00 & 1,62 & , 486 \\
\hline Conhecidos, parentes, amigos e vizinhos & 5005 &, 00 & 1,00 & 1,33 & ,471 \\
\hline Internet & 5005 &, 00 & 1,00 & 1,85 & ,356 \\
\hline \multicolumn{6}{|l|}{ Tipo de cidade } \\
\hline $\mathrm{RMBH}$ & 5005 &, 00 & 1,00 & ,4729 & ,49932 \\
\hline Cidades polo & 5005 &, 00 & 1,00 & ,2186 & ,41333 \\
\hline Cidades pequenas & 5005 & ,00 & 1,00 & ,3085 & ,46192 \\
\hline \multicolumn{6}{|l|}{ Percepção de eficiência } \\
\hline $\begin{array}{c}\text { Percebe a polícia como eficiente não resolução de } \\
\text { problemas de violência }\end{array}$ & 4908 &, 00 & 1,00 & ,6729 & ,46920 \\
\hline
\end{tabular}




\section{Resultados ${ }^{3}$}

Primeiramente, foram calculadas as estatísticas descritivas da confiança nas instituições Poder Judiciário (Justiça), Igreja, Imprensa, Governo Municipal, Governo Estadual e Governo Federal, além da confiança na Polícia a fim de encontrar o nível de confiança da instituição de interesse frente às demais (Tabela 4). Com o intuito de testar a validade da média da confiança na polícia em relação às outras instituições, aplicamos o teste $T$ de comparação de médias para amostras estatísticas pareadas. A estatística de significância utilizada foi $p \leq 0,05$. Consideramos os desvios-padrão relativamente baixos, tendo em vista a amplitude da distribuição das respostas (0 a 10) (Tabela 5). Em seguida, calculamos a correlação de Pearson dessas variáveis, e, por último, a análise de regressão linear com a variável dependente Confiança na Polícia duas a duas (Tabela 6)

Utilizando uma escala de 0 a 10, em que 0 significa "não confio nem um pouco" e o 10 significa "confio muito", os entrevistados responderam o quanto confiam em cada uma das instituições (Tabela 4). A média de confiança na Polícia foi de 5,81, portanto, dentre as 7 instituições avaliadas é a $5^{\mathrm{a}}$ em grau de confiança:

Tabela 4

Estatísticas Descritivas da Confiança nas Instituições (Escala de 0 a 10)

\begin{tabular}{|c|c|c|c|c|c|}
\hline & $N$ & Mínimo & Máximo & Média & Desvio Padrão \\
\hline $\begin{array}{l}\text { Poder Judiciário } \\
\text { (justiça) }\end{array}$ & 4920 & 0 & 10 & 5,58 & 2,896 \\
\hline Igreja & 4962 & 0 & 10 & 7,50 & 2,787 \\
\hline Imprensa & 4901 & 0 & 10 & 6,57 & 2,699 \\
\hline Polícia & 4979 & 0 & 10 & 5,81 & 2,784 \\
\hline Governo Municipal & 4947 & 0 & 10 & 5,45 & 3,053 \\
\hline Governo Estadual & 4909 & 0 & 10 & 6,27 & 2,914 \\
\hline Governo Federal & 4951 & 0 & 10 & 6,38 & 3,059 \\
\hline N Válido (listwise) & 4724 & & & & \\
\hline
\end{tabular}

Fonte: CRISP/UFMG, 2009

A média de confiança recebida pela Polícia $(5,81)$ é maior do que recebem o Governo Municipal $(5,45)$ e o Poder Judiciário $(5,58)$. Por outro lado, a instituição policial recebe menor nível de confiança do que o Governo Estadual (6,27), Governo Federal (6,38), Imprensa $(6,57)$ e Igreja $(7,5)$. Essas médias foram validadas por meio de Teste T para amostras estatísticas pareadas (Tabela 5):

\footnotetext{
${ }^{3}$ Buscamos, inicialmente, realizar uma análise descritiva das variáveis pertinentes ao estudo. Comparamos o nível de confiança na polícia com as demais instituições por meio de estatística descritiva e por Teste T para amostras estatísticas pareadas. Em seguida, realizamos o teste de correlação de Pearson, a fim de verificar a associação entre a confiança nas diferentes instituições. Através da geração de tabelas de contingência, buscamos identificar a distribuição dos indivíduos segundo os níveis de confiança. Por fim, foram testados os efeitos das variáveis dependentes na variável de interesse, confiança na polícia, por meio de regressão linear.
} 
SILVA, G. F.; BEATO, C. Confiança na polícia em Minas Gerais: o efeito da percepção...

Tabela 5

Teste T para amostras

estatísticas pareadas

\begin{tabular}{|c|c|c|c|c|c|c|}
\hline & & Média & $\mathrm{N}$ & Desvio padrão & $\begin{array}{c}\text { Erro } \\
\text { padrão médio }\end{array}$ & Sig. (2-tailed) \\
\hline \multirow[t]{2}{*}{$\begin{array}{c}\text { Par } \\
01\end{array}$} & Poder Judiciário (justiça) & 5,58 & 4907 & 2,896 & ,041 & \multirow[b]{2}{*}{, 000} \\
\hline & Polícia & 5,79 & 4907 & 2,783 & ,040 & \\
\hline \multirow[t]{2}{*}{$\begin{array}{l}\text { Par } \\
02\end{array}$} & & 7,50 & 4938 & 2,789 & ,040 & \multirow[b]{2}{*}{, 000} \\
\hline & Polícia & 5,81 & 4938 & 2,786 & ,040 & \\
\hline \multirow[t]{2}{*}{$\begin{array}{c}\text { Par } \\
03\end{array}$} & Imprensa & 6,57 & 4887 & 2,700 & ,039 & \multirow[b]{2}{*}{,000 } \\
\hline & Polícia & 5,79 & 4887 & 2,782 & 040 & \\
\hline \multirow[t]{2}{*}{$\begin{array}{c}\text { Par } \\
04\end{array}$} & & 5,80 & 4930 & 2,780 & ,040 & \multirow[b]{2}{*}{, 000} \\
\hline & Governo Municipal & 5,45 & 4930 & 3,053 & ,043 & \\
\hline \multirow[t]{2}{*}{$\begin{array}{l}\text { Par } \\
05\end{array}$} & & 5,81 & 4895 & 2,780 &, 040 & \multirow[b]{2}{*}{, 000} \\
\hline & Governo Estadual & 6,27 & 4895 & 2,913 & ,042 & \\
\hline \multirow[t]{2}{*}{$\begin{array}{l}\text { Par } \\
06\end{array}$} & Polícia & 5,81 & 4932 & 2,782 &, 040 & \multirow[b]{2}{*}{,000 } \\
\hline & Governo Federal & 6,38 & 4932 & 3,058 & ,044 & \\
\hline
\end{tabular}

Fonte: CRISP / UFMG, 2009.

Pelo teste de correlação de Pearson (Tabela 6), verifica-se que a associação entre as variáveis, em geral, é alta. Porém, a confiança na polícia é mais correlacionada com a confiança na justiça $(0,522)$. É provável que, dentre as instituições pesquisadas, a confiança no poder judiciário seja a que de fato pode afetar de maneira mais significativa a confiança na polícia, conforme a perspectiva de Goldstein (2003), Muniz (2006) e Santos (2012), que afirmam existir confusão entre as funções do trabalho policial e do sistema de justiça criminal. Esse resultado corrobora diversos autores que tratam, principalmente, da desconfiança nas instituições democráticas no mundo e, sobretudo, na América Latina (MAGalHÃES, 2003; MoIsÉs, 2005; 2010; RoBerTS, 2007). Assim, apesar de a confiança policial ter suas nuances específicas, seu baixo nível pode também fazer parte de um movimento cultural mais abrangente. 
Tabela 6

Correlação de Pearson entre o

nível de Confiança nas Instituições

\begin{tabular}{|c|c|c|c|c|c|c|c|}
\hline & $\begin{array}{c}\text { Poder } \\
\text { Judiciário } \\
\text { (justiça) }\end{array}$ & Igreja & Imprensa & Polícia & $\begin{array}{l}\text { Governo } \\
\text { Municipal }\end{array}$ & $\begin{array}{l}\text { Governo } \\
\text { Estadual }\end{array}$ & $\begin{array}{l}\text { Governo } \\
\text { Federal }\end{array}$ \\
\hline $\begin{array}{c}\text { Poder Judiciário } \\
\text { (justiça) }\end{array}$ & 1 &, $342^{*}$ &, $324^{*}$ &, $522^{*}$ &, $156^{*}$ & ,429* &, $417^{*}$ \\
\hline Igreja &, $342^{*}$ & 1 &, $309 *$ &, $325^{*}$ &, $113^{*}$ & ,292* & ,296* \\
\hline Imprensa &, $324^{*}$ &, $309^{*}$ & 1 &, $383^{*}$ & ,139* &, $377^{*}$ &, $331 *$ \\
\hline Polícia &, $522^{*}$ &, $325^{*}$ &, $383^{*}$ & 1 &, $190^{*}$ & ,490* &, $429 *$ \\
\hline $\begin{array}{l}\text { Governo } \\
\text { Municipal }\end{array}$ &, $156^{*}$ &, $113^{*}$ &, $139 *$ &, $190 *$ & 1 &, $317^{*}$ &, $257 *$ \\
\hline $\begin{array}{l}\text { Governo } \\
\text { Estadual }\end{array}$ &, $429 *$ &, $292^{*}$ &, $377^{*}$ &, $490 *$ &, $317^{*}$ & 1 &, $683^{*}$ \\
\hline Governo Federal &, $417^{*}$ &, $296 *$ &, $331 *$ &, $429 *$ &, $257^{*}$ &, $683^{*}$ & 1 \\
\hline
\end{tabular}

*Sig. $\leq 0,01$ (level 2-tailed).

Ainda pela Tabela 6 , observa-se também alta correlação entre a confiança na polícia e nos governos, especialmente federal $(0,429)$ e estadual $(0,490)$. Goldsmith (2005, p. 445.450) considera impossível analisar a confiança na polícia em separado da confiança nos governos. Afirma que ausência de governo democrático e accountability são comuns em países subdesenvolvidos, que também possuem alto déficit de confiança. Em países democráticos, há maior liberdade para a prática política, viabilizando acordos e comportamentos aprovados pela população e, consequentemente, a confiança. Daí a forte correlação entre confiança na polícia e governos. Como as Polícias Militar e Civil são mais visíveis e são de responsabilidade do governo estadual é plausível haver uma maior correlação entre a confiança na polícia e no governo estadual. Ainda assim, as correlações entre confiança na polícia e nos governos municipal e federal também são elevadas, expressando que a estabilidade e legitimidade do regime político influenciam a confiança na polícia.

Na sequência, as Tabelas 7 e 8 mostram a distribuição dos agrupamentos individuais por variáveis socioeconômicas e demográficas (Tabela 7) e por variáveis de contato com a polícia e percepção de sua atuação (Tabela 8) segundo os níveis de confiança categorizados em Nenhuma, Baixa, Média e Alta: 
SILVA, G. F.; BEATO, C. Confiança na polícia em Minas Gerais: o efeito da percepção...

Tabela 7

Confiança na polícia segundo variáveis socioeconômicas e demográficas (\%)

\begin{tabular}{|c|c|c|c|c|c|}
\hline \multirow{2}{*}{\multicolumn{2}{|c|}{ Variáveis independentes }} & \multicolumn{4}{|c|}{ Confiança na polícia } \\
\hline & & Nenhuma & Baixa & Média & Alta \\
\hline \multirow{3}{*}{ Cidades } & Região metropolitana & 8,2 & 18,2 & 60,5 & 13,0 \\
\hline & Cidades polo & 5,1 & 16,3 & 60,6 & 17,9 \\
\hline & Cidades pequenas & 6,3 & 19,1 & 54,0 & 20,6 \\
\hline \multirow{2}{*}{ Sexo } & Masculino & 6,7 & 18,5 & 58,9 & 15,9 \\
\hline & Feminino & 7,2 & 17,6 & 58,3 & 16,9 \\
\hline \multirow{4}{*}{ Faixa etária } & Abaixo de 25 anos & 9,8 & 23,0 & 58,3 & 8,9 \\
\hline & Mais de 25 a 36 anos & 8,3 & 21,1 & 60,0 & 10,6 \\
\hline & Mais de 36 a 50 anos & 5,2 & 17,1 & 61,5 & 16,1 \\
\hline & Mais de 50 anos & 4,9 & 11,3 & 54,3 & 29,5 \\
\hline \multirow{6}{*}{ Estado civil } & Solteiro & 8,9 & 20,0 & 58,9 & 12,2 \\
\hline & Casado & 5,4 & 16,4 & 60,9 & 17,3 \\
\hline & Amigado & 8,1 & 21,8 & 54,6 & 15,5 \\
\hline & Divorciado & 7,1 & 16,8 & 57,6 & 18,5 \\
\hline & Separado & 2,0 & 15,8 & 49,5 & 32,7 \\
\hline & Viúvo & 5,5 & 11,8 & 49,8 & 32,8 \\
\hline \multirow{6}{*}{ Cor/Raça } & Branco & 5,7 & 16,8 & 62,9 & 14,6 \\
\hline & Preto & 7,6 & 22,3 & 51,8 & 18,3 \\
\hline & Pardo & 7,9 & 18,9 & 57,6 & 15,7 \\
\hline & Amarelo & 11,0 & 24,7 & 49,3 & 15,1 \\
\hline & Indígena & 8,8 & 11,8 & 58,8 & 20,6 \\
\hline & Outro & 8,1 & 8,6 & 47,8 & 35,5 \\
\hline \multirow{7}{*}{ Religião } & Não tenho / pratico religião & 12,0 & 20,3 & 58,0 & 9,8 \\
\hline & Católica Apostólica Romana & 6,1 & 17,1 & 58,3 & 18,5 \\
\hline & Evangélicas & 6,5 & 19,4 & 58,9 & 15,2 \\
\hline & Espírita & 10,2 & 19,7 & 60,5 & 9,6 \\
\hline & Umbanda e Candomblé & & 10,0 & 70,0 & 20,0 \\
\hline & Religiões Orientais & 15,4 & 7,7 & 61,5 & 15,4 \\
\hline & Outra & 10,0 & 23,3 & 56,7 & 10,0 \\
\hline \multirow{9}{*}{ Escolaridade } & Analfabeto & 6,3 & 10,6 & 42,9 & 40,2 \\
\hline & $1^{\text {a a }} 4^{\text {a }}$ série & 5,9 & 13,6 & 51,3 & 29,2 \\
\hline & $1^{\circ}$ grau incompleto & 9,8 & 19,5 & 53,7 & 16,9 \\
\hline & $1^{\circ}$ grau completo & 7,3 & 18,7 & 59,0 & 14,9 \\
\hline & $2^{\circ}$ grau incompleto & 7,7 & 22,6 & 58,4 & 11,3 \\
\hline & $2^{\circ}$ grau completo & 7,2 & 19,6 & 63,8 & 9,3 \\
\hline & Superior incompleto & 6,8 & 19,8 & 66,9 & 6,5 \\
\hline & Superior completo & 2,7 & 18,5 & 72,5 & 6,4 \\
\hline & Pós-graduação & 3,6 & 17,1 & 72,1 & 7,2 \\
\hline \multirow{10}{*}{ Renda familiar } & Até 01 salário mínimo & 6,6 & 17,2 & 50,2 & 26,0 \\
\hline & Mais de 01 até 02 salários & 6,7 & 17,5 & 58,3 & 17,5 \\
\hline & Mais de 02 até 04 salários & 7,7 & 19,0 & 58,5 & 14,8 \\
\hline & Mais de 04 até 07 salários & 6,6 & 18,8 & 63,9 & 10,7 \\
\hline & Mais de 07 até 11 salários & 4,9 & 14,2 & 72,5 & 8,3 \\
\hline & Mais de 11 até 16 salários & 12,2 & 22,4 & 58,2 & 7,1 \\
\hline & Mais de 16 até 25 salários & 3,3 & 25,0 & 70,0 & 1,7 \\
\hline & Mais de 25 até 40 salários & 3,7 & 11,1 & 70,4 & 14,8 \\
\hline & Mais de 40 salários & 11,1 & 22,2 & 55,6 & 11,1 \\
\hline & & 6,9 & 18,1 & 58,5 & 16,5 \\
\hline
\end{tabular}

Fonte: CRISP/UFMG, 2009. 
OPINIÃO PÚBLICA, Campinas, vol. 19, no 1, junho, 2013, p. 118-153

Tabela 8

Confiança na polícia segundo variáveis de contato e percepção da atuação policial (\%)

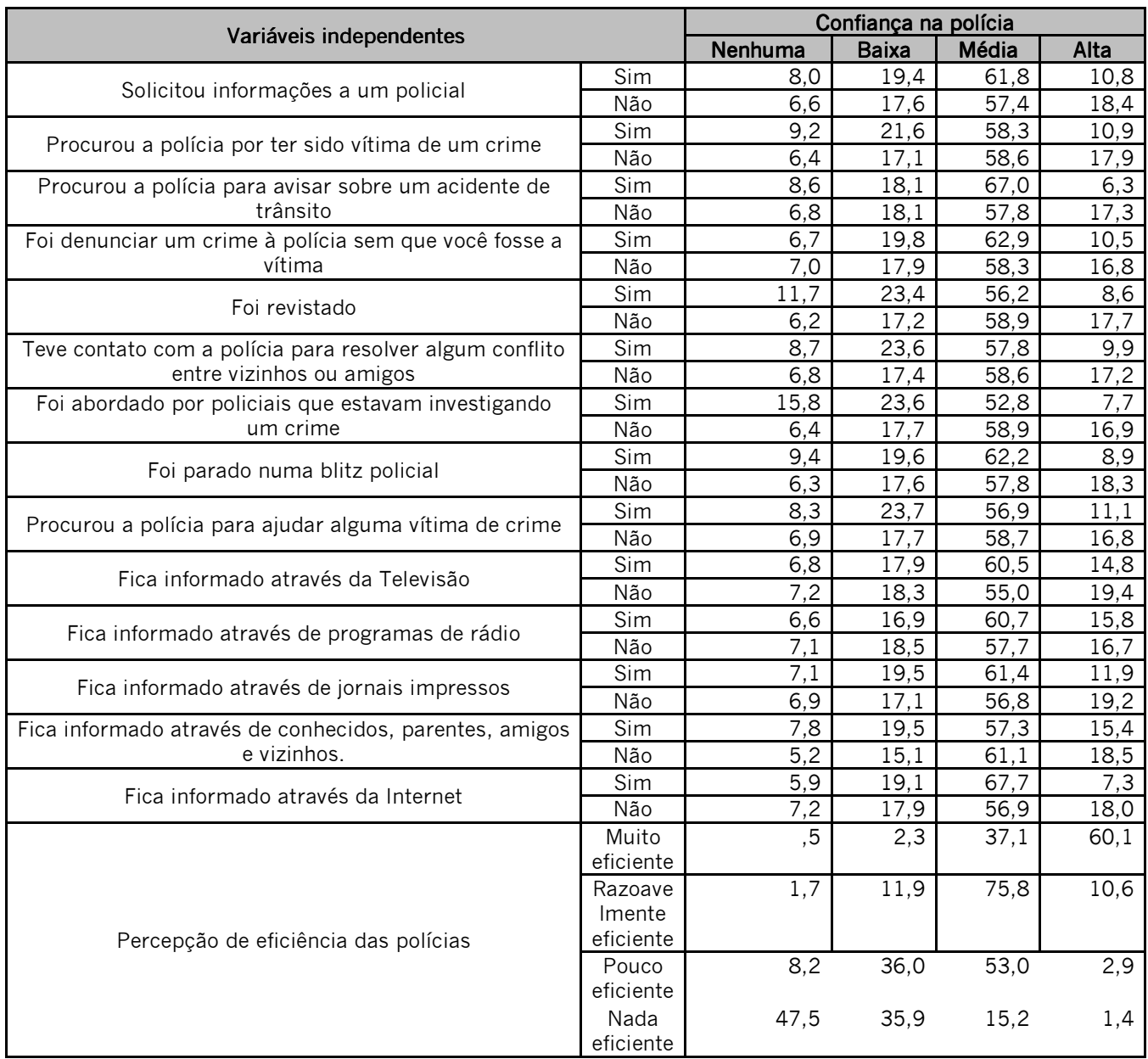

Fonte: CRISP/UFMG, 2009.

A análise das Tabelas 7 e 8, tabelas de contingência da confiança na polícia com as variáveis independentes do estudo, mostra algumas tendências. Observa-se que conforme aumentam os tamanhos da cidade reduz-se a proporção de indivíduos que têm alta confiança na polícia. Tal tendência corrobora a hipótese de que nas cidades pequenas há maior proximidade e menos conflitos entre policiais e cidadãos, o que pode ter origem na própria característica de maior coesão nas menores cidades. As diferenças quanto ao sexo segundo os níveis de confiança são pouco expressivas. Já com relação à faixa etária, verifica-se que quanto mais jovem, maior é a proporção dos que possuem baixa ou nenhuma confiança na polícia. Isso está de acordo com o maior consenso da literatura sobre o tema de que quanto mais velho maior a confiança dos indivíduos nas instituições. Quanto ao estado civil, os solteiros apresentam menor confiança na polícia. De acordo com a raça/cor, negros e indígenas possuem a maior proporção dentre os que apresentam alta confiança e são justamente os indivíduos 
SILVA, G. F.; BEATO, C. Confiança na polícia em Minas Gerais: o efeito da percepção...

que declaram participar de religiões afro que têm mais alta confiança na polícia. Ao considerar a escolaridade, verifica-se que, conforme ela cresce, reduz a proporção daqueles que possuem alta confiança na polícia ao passo que há um aumento progressivo daqueles que possuem média confiança. Segundo a renda, são os indivíduos que ganham até um salário mínimo, portanto, os que ganham menos, que apresentam maior confiança na instituição policial. Conforme aumenta a proporção dos que percebem que a polícia é ineficiente aumenta a proporção dos que possuem nenhuma e baixa confiança na polícia ao passo que reduz a proporção dos que possuem alta. Quanto às variáveis de contato com a polícia, nota-se que aqueles que não mantiveram nenhum tipo de contato têm mais alta confiança do que os que mantiveram. A distribuição da confiança segundo meios de informação apresenta uma distribuição menos bem definida.

A partir da análise de regressão linear (Tabela 9), é possível verificar e analisar os efeitos multivariados dos fatores socioeconômicos e das demais variáveis exploradas sobre a confiança na polícia: 
OPINIÃO PÚBLICA, Campinas, vol. 19, no 1, junho, 2013, p. 118-153

Tabela 9

Modelo Regressão Linear

da Confiança na Polícia

\begin{tabular}{|c|c|c|c|}
\hline & $\begin{array}{c}\text { Coeficientes Não } \\
\text { padronizados }\end{array}$ & $\begin{array}{l}\text { Coeficientes } \\
\text { padronizados }\end{array}$ & Sig. \\
\hline (Constant) & 2,977 & & ,000 \\
\hline \multicolumn{4}{|l|}{ Socioeconômicos } \\
\hline Sexo $($ Masculino $=1)$ & ,008 & 001 & ,909 \\
\hline Idade & 025 &, 147 &, 000 \\
\hline Estado Civil (Casado=1) & $\cdot, 192$ & $\cdot 034$ &, 008 \\
\hline Branco/Não Branco $($ Branco=1) & ,034 &, 006 & ,615 \\
\hline Ter religião & ,388 & ,043 &, 000 \\
\hline Escolaridade - até $8^{\text {a }}$ Série $/+$ que $8^{\text {a }}$ Série $\left(+\right.$ que $8^{\text {a }}$ Série $=1$ ) & $\cdot, 198$ & $\cdot, 036$ &, 011 \\
\hline Renda - Até 2 SM/Mais de 2 SM (Mais de 2 Salários Mínimos=1) & $\cdot, 237$ & $\cdot, 043$ &, 001 \\
\hline \multicolumn{4}{|l|}{ Contato direto com a polícia - voluntário } \\
\hline Solicitou informações & ,070 & ,011 & ,403 \\
\hline Procurou por ser vítima de crime & $\cdot, 243$ & $\cdot, 036$ &, 004 \\
\hline Procurou para avisar sobre acidente de trânsito & $\cdot, 274$ & $\cdot, 026$ &, 043 \\
\hline Informou-se sobre crime por policiais & ,799 & 053 &, 000 \\
\hline \multicolumn{4}{|l|}{ Contato direto com a polícia - compulsório } \\
\hline Foi revistado & $\cdot, 257$ & $\cdot, 033$ &, 018 \\
\hline Teve contato para resolver conflito entre vizinhos/amigos & $\cdot, 154$ & $\cdot, 017$ &, 162 \\
\hline Foi abordado em investigação de crime & $\cdot, 411$ & $\cdot, 034$ & ,007 \\
\hline Foi parado numa blitz & -, 146 & $\cdot, 021$ & , 120 \\
\hline \multicolumn{4}{|l|}{ Contato indireto/informou - sobre crime por... } \\
\hline Televisão & ,075 & 013 & ,453 \\
\hline Rádio & ,038 & ,006 &, 618 \\
\hline Jornais impressos & $\cdot, 148$ & $\cdot, 026$ &, 074 \\
\hline Conhecidos, parentes, amigos e vizinhos & $\cdot, 415$ & $\cdot, 070$ &, 000 \\
\hline Internet & ,292 & 038 &, 005 \\
\hline \multicolumn{4}{|l|}{ Tipo de cidade } \\
\hline Cidades polo & ,335 & ,050 & ,000 \\
\hline Cidades pequenas & ,387 & ,064 &, 001 \\
\hline \multicolumn{4}{|l|}{ Percepção de eficiência } \\
\hline Percebe a polícia eficiente na resolução de problemas de violência & 2,880 & 487 & ,000 \\
\hline
\end{tabular}

$\mathrm{R}^{2}=0,331 \mathrm{R}^{2}$ Ajustado $=0,328$.

Os resultados apresentados na Tabela 9 estão de acordo com o maior consenso da bibliografia sobre o que afeta a confiança na polícia, que é o efeito da idade. Idade é significativa e apresenta 
SILVA, G. F.; BEATO, C. Confiança na polícia em Minas Gerais: o efeito da percepção...

impacto de 0,025 pontos na escala de confiança para cada ano a mais de vida. Os coeficientes padronizados mostram que ela é segunda variável que mais influencia a confiança. Conforme diversos autores têm afirmado, os jovens são mais propícios a perceberem a ação policial como desleal, injusta e inadequada (BRown \& BENEDICT, 2002; BRUNSON \& MILleR, 2006, p. 623). Como explicação para isso, Bittner (2003) afirma que os jovens são inclinados à má conduta e atitudes favorecem o conflito com policiais. Como jovens são os principais contraventores, a culpabilidade é um fator que afeta negativamente sua confiança.

As variáveis indicadoras de status socioeconômico, escolaridade e renda obtiveram significância estatística e efeitos negativos de -0,198 e -0,237 pontos na escala, respectivamente. Esses resultados não seguem a lógica, ao menos à primeira vista, da perspectiva de Adorno (1994), Belli (2004), Bowling e Foster (2002), Costa (2004b), Krok (2008), Mesquita Neto (1999), Pinheiro (1997) Rothstein e Uslaner (2005), dentre outros, de que a polícia trata grupos sociais desprivilegiados de forma negativamente desigual. Nesse viés, os grupos de maior escolaridade e renda deveriam ter maior nível de confiança na instituição por receberem melhor tratamento, entretanto, ocorre o contrário.

A afirmação de Cao (2011) de que os grupos dominantes perceberiam a polícia como aliadas não encontra respaldo empírico no estado de Minas Gerais. As pesquisas sobre confiança na polícia até então realizadas no Brasil, que foram de Oliveira (2011) e Lopes (2010), não encontram resultados estatisticamente significativos para renda e não incluem essa variável na sua análise quantitativa.

Anos de estudo reduzem a confiança na polícia, de acordo com Oliveira (2011, p. 12; 16), Brown \& Benedict (2002, p. 554; 551) e Paixão \& Beato (1997, p. 242), dentre outros. Os anos estudados a mais fazem com que 0 indivíduo se torne mais crítico à polícia e a considere com menor legitimidade e eficiência. Nossos resultados também estão mais de acordo com Macdonald et al (2007, p. 26) e Weitzer \& Tuch (2004) ao encontrarem que alto status socioeconômico associa-se à percepção de tratamento desleal e injusto. A hipótese mais plausível para explicar esse resultado é de que os indivíduos com maior renda e anos de estudo são mais críticos e exigentes quanto à atuação da polícia enquanto aqueles que sofrem mais veementemente a sua repressão e possuem menor renda e escolaridade são menos exigentes.

Divergindo da consistência do efeito da raça na maioria dos estudos, especialmente nos Estados Unidos, onde grupos minoritários como negros têm menor confiança na polícia (BRoWN \& Benedict, 2002, p. 544; FAgan, 2008, p. 123; Frank et al, 2005, Howell, 2004; HURST et al, 2000; MACDONALD et al, 2007, p. 30; MyHILl \& BeAK, 2008; TAXMAN et al, 2005; TYLeR, 2005; WARREN, 2005), não encontramos efeitos estatisticamente significativos para a variável raça, diferente inclusive de Oliveira (2011), que estuda a realidade brasileira.

A hipótese explicativa para esse resultado é que as justificativas de Brown \& Benedict (2002, p.548) para a pior percepção dos negros americanos sobre a polícia não são facilmente aplicadas para a realidade mineira, ou seja, negros ou não brancos não se aglutinam tão facilmente como grupos como nos Estados Unidos. Nem mesmo a divisão entre negros e brancos é tão evidente. As comunidades locais são mais mistas ou mestiças do que as americanas. Apesar de haver maior probabilidade de negros, comparados aos brancos brasileiros, morarem em áreas deterioradas, há grande proporção de brancos compartilhando esses espaços. 
Divergindo do que é mais intuitivo e encontrado por Macdonald et al (2007, p. 26) e Cao (2011, p. 13), ser casado, apesar de ter significância estatística, apresenta efeito negativo de $\cdot 0,192$ pontos na escala de confiança na polícia. A presumida menor probabilidade de conflito entre casados e polícia, tal como ser do sexo feminino, não aumenta sua confiabilidade no estado de Minas Gerais. Dado o caráter inusitado desse resultado, utilizando o método Enter no SPSS, rodaram-se modelos de regressão cuja primeira variável independente inserida foi o estado civil. As demais variáveis sociodemográficas foram inseridas uma a uma em regressões seguintes. Notou-se que ser casado é estatisticamente significativo, com efeito positivo na confiança por volta de 0,300 até que a variável idade é inserida no modelo. A idade apresenta efeito tão forte que inverte o sinal do estado civil. Logo, deve-se ter cautela para assumir que "ser casado reduz a confiança na polícia em Minas Gerais". Cruzamento também demonstra que casados confiam mais na polícia do que não casados.

Ter religião é significativo e apresenta efeito positivo de 0,388 pontos na escala de confiança na polícia. Esse resultado está de acordo com a maioria das pesquisas, corroborando que, por meio da religião, o cidadão expressa sua ligação com a comunidade, assimilando mais facilmente as normas, tornando-se mais propenso à cooperação, à reciprocidade, e à contenção de riscos, elevando a confiança nas instituições (conforme Moisés, 2005).

A variável sexo não produziu resultados estatisticamente significativos. De acordo com Avdija (2010, p. 85), a literatura indica que mulheres tendem a avaliar melhor a polícia do que os homens. Entretanto, o mesmo encontra resultado divergente, reforçando Brown \& Benedict (2002, p. 554) ao dizer que não há consenso sobre os efeitos do gênero para as atitudes em relação à polícia.

Conforme Avdija (2010, p. 85-86), há evidências empíricas de que a experiência pessoal com a polícia se inter-relaciona com status socioeconômico, gênero e raça. Considera-se que, quando o contato com a polícia se dá por iniciativa do cidadão, aumentam as chances de haver confiança em detrimento de quando a polícia inicia o contato (AVDIJA, 2010, p. 79; BRown \& BENEDICT, 2002; KÄÄRIÄINEN, 2008; KÄ̈̈RIÄINEN \& SIRÉN, 2011; MYHILL \& BEAK, 2008, p. 05).

Em nossa análise, encontramos que a maior parte dos contatos com a polícia, sejam eles compulsórios ou voluntários, provoca efeitos negativos no nível de confiança, mas o efeito do contato compulsório é negativamente mais elevado. Mesmo ter procurado a polícia para informar acidente de trânsito e por ser vítima de crime tem associação negativa com a confiança policial. Possivelmente, o fato de ter sido vítima de crime gera a impressão de que a polícia é ineficiente no enfrentamento da criminalidade, trazendo como consequência a descrença de que a instituição esteja cumprindo bem a sua função. Entretanto, é improvável que a polícia seja tida como responsável por evitar os acidentes de trânsito.

Das variáveis de contato direto, apenas informar-se sobre crime por policiais apresenta efeito positivo e estatisticamente significativo. Ainda, isso pode ocorrer por causalidade reversa, ou seja, não é o fato de informar-se por policiais que aumenta a confiança, mas, informam-se por eles quem já tem relação de conhecimento e confiabilidade com a polícia. Esses resultados podem indicar que a desconfiança pode ser baseada em procedimentos, conforme proposto por Tyler (2005). Os indícios são de que os procedimentos ou tratamento dos policiais não favorecem a confiança quando a polícia e cidadãos se encontram, já que quase todo tipo de contato com a polícia reduz sua confiabilidade. 
SILVA, G. F.; BEATO, C. Confiança na polícia em Minas Gerais: o efeito da percepção...

Corroborando Kääriäinen (2008, p. 142), que afirma que, além da experiência pessoal, a confiança na polícia é construída por imagens e história, encontramos efeitos significativos das variáveis informar-se sobre crimes por jornais impressos, por conhecidos, amigos, parentes e vizinhos. A hipótese é que jornais e conversas entre amigos e vizinhos geram a impressão de que há muita violência, logo, de que a polícia não está conseguindo cumprir bem sua função. TV, rádio e internet não foram significativas.

O tamanho da cidade interfere na sociabilidade (SIMMEL, 1987) e a distribuição dos crimes violentos em Minas Gerais segue padrões de acordo com tipos de cidade (BEato, 1998; 2010). Proximidade e visibilidade indicam a disponibilidade e acessibilidade da polícia, reduzindo o medo do crime, o que faz a confiança aumentar (FRANK et al, 2005; KÄÄRIÄINEN, 2008, p. 148).

Pelo critério de colinearidade, os três tipos de cidade categorizados não entram no modelo ao mesmo tempo. Ser morador de cidades "polo regional" e cidades com "menos de 10.000 habitantes" (pequenas) obtiveram significância estatística e apresentam efeitos positivos no nível de confiança na polícia de 0,335 e 0,387 pontos, respectivamente. A despeito disso, morar na RMBH reduz consideravelmente o nível de confiança. Tanto a proximidade quanto a visibilidade da polícia ocorrem mais facilmente nas cidades de menor porte. Logo, tem-se maior probabilidade de haver maior conhecimento e coesão entre policiais e cidadãos, o que favorece a confiança.

A variável de percepção de eficiência na resolução de problemas relacionados à violência foi significativa e apresentou maior efeito na confiança na polícia dentre todas no modelo $(2,887)$. Perceber a polícia como eficiente ou razoavelmente eficiente produz forte efeito sobre o nível de confiança nela. 0 efeito dessas variáveis eleva os achados de Goldstein (2003), que trata da associação que o senso comum faz entre polícia e sistema de justiça, atribuindo à polícia a função de controlar o crime. Ser vitimado ou ter a impressão de que a violência aumentou é interpretado como falta de eficiência policial em controlar a violência. Logo, a polícia não atende às expectativas da população, gerando desconfiança.

Resumindo nossos achados, ter maior renda, maior escolaridade, ser casado, informar-se sobre crime por parentes, amigos e vizinhos ou jornais impressos, ter procurado a polícia por ter sido vítima de um crime ou para informar sobre acidente de trânsito, ter sido revistado ou abordado em uma investigação de crime e morar na RMBH reduzem a confiança na instituição policial. Por outro lado, aumentam o nível de confiança ser mais velho, ter religião, informar-se sobre crime por policiais ou pela internet, morar em cidades que são polos regionais ou tenham menos de 10.000 habitantes e, principalmente, perceber a polícia como eficiente ou razoavelmente eficiente para resolver problemas relacionados à violência na cidade.

\section{Considerações Finais}

Neste artigo, analisamos a confiança na polícia do estado de Minas Gerais identificando alguns fatores que a afetam. Pelo levantamento bibliográfico, encontramos que, dentre os principais fatores que influenciam a confiança individual na instituição, estão características sociodemográficas, contato ou conhecimento da mesma e percepção de eficiência da instituição. Outros aspectos relevantes não foram enfocados por não poderem ser testados aqui. 
Estudos empíricos sobre a confiança na polícia têm ganhado espaço em diversos países, havendo considerável número de estudos quantitativos disponíveis, o que não ocorre no Brasil. De acordo com Avdija (2010, p. 76.77), a maioria dos estudos focam no status socioeconômico, tipos de contato com a polícia (iniciado pelo cidadão ou pela polícia), satisfação com os serviços prestados, experiências pessoais com a polícia, efeito da mídia, da idade, gênero e raça. Por se optar pela análise da confiança dos indivíduos na polícia em nível individual, não foi dedicada maior atenção para o papel das características culturais, históricas e organizacionais da instituição. Não pretendemos, neste artigo, esgotar todos os elementos que possam interferir na confiança na polícia, mas analisar os principais, de acordo com a bibliografia consultada, e para os quais fossem possíveis verificar os indícios empíricos da interferência segundo os dados ao nosso alcance.

A confiança na polícia em Minas Gerais deve ser tratada dentro de um contexto de redução da confiança nas instituições democráticas no mundo em geral. Conforme Goldsmith (2005), a confiança na polícia guarda correlação com a confiança nos governos e no regime político. Daí a associação encontrada entre a confiança na polícia e nos governos. Entretanto, a instituição que tem maior potencial de influenciar a confiança na instituição policial é o Poder Judiciário, pela associação e confusão que o público faz sobre a função dessas instituições. A confiança no Poder Judiciário (Justiça) é a que possui maior associação com a confiança na polícia.

Quanto ao efeito das variáveis sociodemográficas, a raça, ao contrário dos diversos países e mesmo de pesquisa realizada no Brasil, não obteve significância estatística para explicar a variação no nível de confiança na instituição policial. Isso é atribuído a não tão clara associação/separação entre os grupos de brancos e não brancos no Brasil ou Minas Gerais, o que ocorre mais facilmente nos Estados Unidos, por exemplo.

Ter religião favorece o desenvolvimento e manutenção de valores que tornam os indivíduos mais recíprocos, propensos à cooperação e integrados à comunidade. Ademais, indivíduos religiosos tendem a evitar conflitos e injustiças e aceitar mais facilmente a legitimidade das autoridades.

Altas renda e escolaridade afetam negativamente a confiança na polícia. Ainda que, para diversos autores, a polícia atue de forma a conter os grupos mais desprivilegiados da sociedade sendo consideravelmente repressiva, as elites não consideram a polícia como aliada e a veem com desconfiança. Os anos de estudo a mais tornam os indivíduos mais críticos à atuação policial. A proposição de Goldstein (2003) de que a polícia tem comportamento assistencialista em bairros pobres pode ser uma explicação para que indivíduos de baixa renda tenham maior confiança. Entretanto, não foi possível testar isso empiricamente, o que deve ser esmiuçado em pesquisas futuras. Nossa principal hipótese é que indivíduos de menor status socioeconômico sejam menos críticos e exigentes em relação ao trabalho policial. Isso pode revelar certa imaturidade dos cidadãos brasileiros, no caso mineiros, quanto ao reconhecimento dos direitos civis na sociedade democrática. Principalmente os mais pobres tendem a apoiar comportamentos autoritários com maior frequência (MoIsés, 2008; PANDOLFI, 1999).

O achado mais negativo para a instituição policial foi que todas as formas de contato direto com a polícia, exceto quando o indivíduo se informa sobre crime e solicita informações a policiais, afeta negativamente a confiança. $\mathrm{O}$ contato direto exerce efeito ainda mais negativo quando é compulsório (ou iniciado pela polícia). A abordagem da polícia constrange o suficiente para que o cidadão passe a não 
SILVA, G. F.; BEATO, C. Confiança na polícia em Minas Gerais: o efeito da percepção...

confiar na instituição. Como a avaliação dos procedimentos policiais serve de base para a confiança procedimental, depreende-se que os procedimentos da polícia, sua eficiência e maneira como lida com os cidadãos afetam negativamente a percepção que se tem dela.

Dentre as variáveis de contato direto, as conversas com terceiros produzem maior impacto negativo na confiança. Pode ser entendida como um contato vicário com a polícia e tal como contato direto afeta negativamente a confiança na instituição policial. Conversas com conhecidos e matérias dos jornais geram a impressão de que esteja ocorrendo alto grau de violência, o que prejudica a percepção de eficiência policial no combate ao crime.

O tamanho da cidade impacta a confiança. Morar na RMBH reduz a confiança enquanto morar em cidades polo regionais e pequenas a aumenta. É provável que haja maior visibilidade e proximidade, causando a impressão de acessibilidade dos policiais para os cidadãos em cidades pequenas, favorecendo a confiança. Provavelmente, há maior conhecimento, até mesmo relação de amizade entre policial e cidadão nessas cidades. Ademais, há maior coesão social, o que favorece a cooperação. Os índices de crime também são menores.

Perceber que a instituição tem bom desempenho em cumprir a função a qual é designada é condição determinante para que receba confiança, conforme afirmam Hudson (2006), Koury (2002), Magalhães (2003), Moisés (2005; 2008), Rothstein e Uslaner (2005), Stoutland (2001), o que é coerente com os resultados aqui encontrados.

Ainda há muito o que explorar acerca da confiança na instituição policial no Brasil. Este artigo deixa algumas lacunas, tais como pouca exploração dos aspectos culturais, históricos e organizacionais da instituição policial. Não se analisou qual o papel do desempenho da polícia no nível de confiança por falta de elementos empíricos para tanto. Mas, em pesquisas futuras, há que se incluir, por exemplo, o tempo de resposta da polícia ao ser acionada. Há que se explorar ainda muito mais fatores que têm potencial de interferir na confiança policial que aqui sequer foram mencionados.

O desenvolvimento de mais pesquisas sobre a confiança na polícia no Brasil permitirá verificar a consistência dos resultados encontrados neste artigo. Pode-se dizer que o campo da confiança na polícia começa a ser explorado agora no país. Além da confiança na instituição de maneira ampla, devem-se analisar especificamente tipos de policiamentos a exemplo do que Goldsmith (2005) procura fazer acerca das reformas ocorridas nas polícias de diversos países e do que Stoutland (2001) realizou em Boston, analisando as dimensões da confiança entre moradores e o policiamento comunitário.

Já que se considera que a confiança na instituição policial é importante, deve-se também estudar como ela poderia ser produzida e sustentada. Para Goldsmith (2005), isso é possível pelo aumento da proximidade entre policiais e cidadãos e da transparência das ações da polícia. Cabe verificar se o mesmo é eficaz no cenário brasileiro. A implantação de policiamento comunitário é tida como benéfica à confiança, entretanto, no Brasil não há estudos publicados que tratem especificamente sobre isso.

Para Brown \& Benedict (2002), os diferentes efeitos que as diferentes combinações de variáveis produzem nas atitudes em relação à polícia ainda devem ser analisados. Devem-se explorar variáveis individuais e contextuais e, ainda, levar em conta aspectos históricos e culturais. Há muito a se pesquisar nesse campo, que é novo e promissor. Nesse sentido, esperamos que este artigo contribua, 
ainda que modestamente, para seu desenvolvimento. Para que haja maior confiança na polícia, os resultados encontrados indicam a necessidade de que os encontros entre polícia e cidadão sejam qualificados, que haja melhoria na relação entre polícia e jovens, que a imprensa escrita não favoreça a impressão de aumento da violência, que o crime reduza, o indivíduo perceba a polícia como eficiente e que diminua a confusão existente entre o que é tido como função do sistema de justiça criminal e da polícia.

\section{Referências Bibliográficas}

Adorno, S. "Violência, controle social e cidadania: dilemas da administração da Justiça Criminal no Brasil". Revista Crítica de Ciências Sociais, n 41, p. 101-127, dez. 1994.

ALtheide, D. L. "The Mass Media, Crime and Terrorism". Journal of International Criminal Justice, 2006.

AvDIJA, S. "The role of police behavior in predicting citizens' attitides toward the police". Applied Psychology in Criminal Justice, 6, 2010.

BAStos Neto, O. "Sociologia política: razões de Estado versus razões de classe: origens republicanas das ideologias de controle e repressão no Brasil". Maiêut. dig. R. Fil. Ci. afins, Salvador, vol. 1, n 1, p. 112-135, maio-ago. 2006.

Beato F. C. C. "Determinantes da criminalidade em Minas Gerais". Revista Brasileira de Ciências Sociais [online], vol.13, n³7, p. 74.87, 1998

Crime e Cidades. Belo Horizonte, p. 289 Tese Titular. SOA/UFMG, 2010.

BeLLI, B. "Violência Policial e Segurança Pública: democracia e continuidade autoritária no Brasil contemporâneo". Impulso, Piracicaba, 15(37), p. 17.34, 2004

BItTner, E. Policiando jovens: o contexto Social da prática Diária. In: BITtner, E. Aspectos do Trabalho Policial. Coleção Polícia e Sociedade 8. São Paulo: EDUSP, p. 303-326, 2003.

BoWling, B.; Foster, J. Policing and the police. The Oxford Handbook of Criminology. Oxford University Press, p. $980 \cdot 1033,2002$

BRoWn, B.; BenEDICT, W. R. "Perceptions of the police: past findings, methodological issues, conceptual issues and policy implications". Policing, 25, p. 543-580, 2002.

BRUnSON, R. K.; MiLleR, J. "Young black men and urban policing in the United States". British Journal of Criminology, p. $613-640,2006$

Cano, I. Controle de Polícia no Brasil. Instituto sou da Paz. Disponível em: http://www.soudapaz.org/premiopolicia2006/textocanoppc.pdf. Acesso em: 15 mar. 2011

CAO, L. "Visible minorities and confidence in the police". Canadian Journal of Criminology and Criminal Justice, vol. 53, $n^{\circ} 1$, p. $1 \cdot 26$, jan. 2011.

CoelHo, E. C. "Criminalização da marginalidade e a marginalização da criminalidade". Revista de Administração Pública, vol. 12, n² 2, p. 139-161, abr.jun. 1978.

CostA, A. T. M. "As reformas nas polícias e seus obstáculos: uma análise comparada das interações entre a sociedade civil, a sociedade política e as polícias". Civitas, Porto Alegre, vol. 8, n³, p. 409-427, set.-dez. 2008.

CostA, N. R. Polícia, controle social e democracia. In: A. T. M. (org.). Entre a lei e a ordem. Rio de Janeiro: FGV, $2004 a$. "Ofício de Polícia, Violência Policial e Luta Por Cidadania Em Mato Grosso". São Paulo em Perspectiva, vol. $18, n^{\circ} 1$, p. $111 \cdot 118,2004 b$.

CRISP - Centro de Estudos de Criminalidade e Segurança Pública / UFMG. Pesquisa de Vitimização e Percepção de Medo em Belo Horizonte e Minas Gerais, 2009. 


\section{SILVA, G. F.; BEATO, C. Confiança na polícia em Minas Gerais: o efeito da percepção...}

DANCEY, C. P. Estatística sem matemática para Psicologia. Porto Alegre: Artmed, 2006.

Fagan, J. Legitimacy and criminal justice. 6 Ohio St. J. Crim. L. 123, 2008.

Frank, J. et al. "Exploring the Basis of Citizens' Attitudes Toward the Police". Police Quarterly, vol. 8, n² 2, p. 206-228, June 2005

Goldsmith, A. "Police reform and the problem of trust". Theoretical Criminology, 9, p. 443.470, nov. 2005.

GoldsteIn, H. Policiando uma sociedade livre. São Paulo: Editora da Universidade de São Paulo, 2003.

Herrmann, S. et al. "Confidence in the Criminal Justice System in the Americas". Americas Barometer Insights, $\mathrm{n}^{\circ} 62$, 2011. Disponível em: <www.AmericasBarometer.org>. Acesso em: 01 dez. 2011.

HowelL, E. S. et al. "Black cities/white cities: evaluating the police". Political Behavior, vol. 26, n 1, p. 45.68, March, 2004.

HUdSon, J. "Institutional Trust and Subjective Well-Being across the EU”. Kyklos, vol. 59, p. 43-62, 2006.

HURST, Y. et al. "The attitudes of juveniles toward the police: a comparison of black and white youth". Policing: An International Journal of Police Strategies \& Management, vol. 23, n² 1, p. 37.53, 2000.

IPEA - Instituto de Pesquisa Econômica Aplicada. O Sistema de Indicadores de Percepção Social (SIPS) - Segurança Pública (2011). Disponível em: <http://www.ipea.gov.br>. Acesso em: abr. 2011.

KÄÄRIÄINEN, J. "Why do the finns trust the police?" Journal of Scandinavian Studies in Criminology and Crime Prevention, vol. 9, n², p. 141-159, 2008.

SIRÉN, R. "Trust in the police, generalized trust and reporting crime". European Journal of Criminology, vol. 8, $\mathrm{n}^{\circ} 1$, p. 65-81, 2011.

KAHN, T. Segurança pública e trabalho policial no Brasil. In: Promoting Human Rights through good governance in Brazil. Centre for Brazilian Studies, University of Oxford: 2003 (conference).

KouRY, M. G. P. "Confiança e Sociabilidade. Uma análise aproximativa da relação entre medo e pertença". Revista Brasileira de Sociologia da Emoção, João Pessoa, vol.1, n², p. 171-206, ago. 2002.

KRok, J. T. O vínculo constitucional entre o Exército e as Polícias Militares: reflexos na estrutura organizacional, formação e prática profissional (1934 - 1988). Vitória, Dissertação de Mestrado, Programa de Pós-Graduação em História Social das Relações Políticas, do Centro de Ciências Humanas e Naturais da Universidade Federal do Espírito Santo, 2008.

LIMA, R. O. Análise das representações sociais da polícia: um estudo da produção de rap e da relação polícia e juventude. Monografia de Graduação, ESDHC/SENASP, Belo Horizonte, 2009.

LOPES, C. S. "Por que os brasileiros desconfiam da polícia? Uma análise das causas da desconfiança na instituições policial". In: $7^{\circ}$ Encontro da Associação Brasileira de Ciência Política (ABCP), 2010, Recife. AT02 - Cultura Política e Democracia, 2010.

Macdonald, J. M. et al. "Race, Neighborhood Context, and Perceptions of Injustice by the Police in Cincinnati". Urban Studies, 13, p. 2567-2585, 2007.

MagalHães, P. "A Confiança nos Parlamentos Nacionais: Regras Institucionais, Representação e Responsabilização Política". Análise Social, vol. XXXVIII, 167, p. 443-465, 2003.

MARINHO, K. R. L. Mudanças organizacionais na implementação do policiamento comunitário. Belo Horizonte, Dissertação de Mestrado, SOA/UFMG, 2002.

MAWBY, R. C. Chibnall revisited: crime reporters, the police and 'Law-and-Order News'. Brazilian Journal of Criminology, vol. 50, n6, p. 1060-1076, 2010.

Mesquita Neto, P. Violência policial no Brasil: abordagens teóricas e práticas de controle. In: PANDolfi, D.C. et al (orgs.). Cidadania, justiça e violência. Rio de Janeiro: Ed. FGV, 1999.

MISSE, M. Crime e violência no Brasil contemporâneo: estudos de sociologia do crime e da violência urbana. Rio de Janeiro: Lúmen Júris, 2007. 
MoısÉs, J. A. "A desconfiança nas instituições democráticas". Opinião Pública, Campinas, vol. XI, n 1, p. 33.63, Março, 2005.

“Cultura Política, Instituições e Democracia: lições da experiência brasileira”. Revista Brasileira de Ciências Sociais, vol. $23, n^{\circ} 66,2008$.

A confiança e os seus efeitos nas instituições democráticas. In: Moısés, J. Á. (Org.). Democracia e confiança: por que os cidadãos desconfiam das instituições públicas?. São Paulo: Editora Edusp, 2010.

Moore, D. A. Estatística Básica e sua prática. Rio de Janeiro: Ed. LTC, 2000.

Muniz, J. Ser policial é, sobretudo, uma razão de ser: cultura e cotidiano da Polícia Militar do Estado do Rio de Janeiro. Rio de Janeiro, Tese de Doutorado, Instituto Universitário de Pesquisas, 1999.

Discricionariedade policial e a aplicação seletiva da lei na democracia. Algumas lições extraídas de Carl B. Klockars", NEV.USP, 2006.

MyHILL, A.; BEAK, K. "Public confidence in the police". Research, Analysis and Information. National Police Improvement Agency - NPIA, 2008.

NoRRIS, P. Critical Citizens: Global Support for Democratic Government. New York: Oxford University Press, 1999.

OliveIRA, J. A. "Dá para confiar nas polícias? Confiança e percepção social da polícia no Brasil". Revista Brasileira de Segurança Pública, São Paulo, Ano 5, Ed. 9, ago.-set. 2011.

PANDolfI, D.C. et al. Cidadania, justiça e violência. Rio de Janeiro: Ed. FGV, 1999.

PAIXÃo, A. L. "A violência urbana e sociologia: sobre crenças e fatos e mitos e teorias e políticas e linguagens". Religião e Sociedade, vol.15, $\mathrm{n}^{\circ}$ 1, Iser/CER, 1990.

Crime, controle social e consolidação da cidadania. In: REIS, F. \& O'DONNELL, G. (eds.). A democracia no Brasil. São Paulo: Vértice. p. 168-199, 1997.

.; BeAto, C. C. "Crimes, vítimas e policiais". Tempo Social: Revista de Sociologia da USP, São Paulo, vol. 9 , $n^{\circ} 1,233 \cdot 248$, maio de 1997

PansinI, D. Confiança nas Instituições. Futura net, 2009. Disponível em: <http://www.futuranet.ws>. Acesso em: jun. 2011.

PINHEIRO, P. S. "Violência, crime e sistemas policiais em países de novas democracias". Tempo Social: Revista de Sociologia da USP, São Paulo, vol. 9, n 1, p. 43-52, 1997.

RenNó, L. R.; SMITH, A. E.; Lloyd, M. L.; PereiRA, F. Legitimidade e qualidade da democracia no Brasil: uma visão da cidadania. São Paulo: Intermeios; Nashville: LAPOP, 2011

RIBEIRO, L. M. L.; SILVA, K. A. "As relações entre direitos humanos e práticas dos policiais civis: o papel da percepção dos cidadãos". Revista Debates, Porto Alegre, vol. 4, n² 2, p. 178.208, jul.-dez. 2010.

RIBEIRO, L. M. L. et al. Relação indivíduo e instituição total: socialização, controles e coesão internos em uma organização policial. Revista do Serviço Público, Brasília, vol. 56, n 3, p. 295-308, jul.-set, 2005.

RoBerts, J. V. "Public confidence in criminal justice in Canada: a comparative and contextual analysis". Canadian Journal of Criminology and Criminal Justice, p. 155-184, 2007.

Rothstein, B.; Uslaner, E. M. “All for One: Equality, Corruption, and Social Trust”. World Politics - vol. 58, n 1 , p. $41 \cdot 72$, oct. 2005.

Santos, M. R. Dimensões da percepção sobre a polícia militar de minas gerais pela população de Belo Horizonte. $34^{\circ}$ Encontro Anual da Associação Nacional de Pós-Graduação e Pesquisa em Ciências Sociais - ANPOCS, Caxambu, 2010.

Trabalho Policial e Lei: um estudo de caso da PMMG em Belo Horizonte. 2012. Belo Horizonte: Dissertação de Mestrado, SOA/UFMG, 2012.

Seligson, M. A.; Booth, J.; Gomez B., M. "Os contornos da cidadania crítica: explorando a legitimidade democrática". Opinião Pública, vol. 12, n 1, p. 1·37, 2006.

SILVA, G. F. "Considerações sobre criminalidade: marginalização, medo e mitos no Brasil". Revista Brasileira de Segurança Pública. São Paulo, Ano 05, Edição 08 fev/mar 2011. 


\section{SILVA, G. F.; BEATO, C. Confiança na polícia em Minas Gerais: o efeito da percepção...}

2012.

. Confiança na polícia em Minas Gerais: o que importa?Belo Horizonte: Dissertação de Mestrado, SOA/UFMG,

.; BRAGA, M. A. F. "Sobre violência e imprensa: Jornais populares versus jornais de qualidade o caso de Minas Gerais”. Argumentos (Unimontes), vol. 5, p. 10-29, 2012.

SILVA, L. A. M. Polícia e segurança pública no Rio de Janeiro de hoje: uma tomada de posição. In: OLIVEIRA, K. B.; OLIVEIRA, G. G. (Org.). Olhares sobre a prevenção a criminalidade. Belo Horizonte: Instituto Elo, p. 35.62, 2009.

Simmel, G. A metrópole e a vida mental. In: VelHo, O. G. (org.). O Fenômeno Urbano. Rio de Janeiro: Ed. Guanabara, 1987.

SkogAn, W. G. "Reporting crimes to the police: the status of world research". Journal of Research in Crime and Delinquency, vol. 21, n², p. 113-137, May, 1984

Stancik, M. A. De médico a homem de ciência: a eugenia na trajetória de Aleixo de Vasconcellos no início do século XX. Paraná: Tese de Doutorado, Universidade Federal do Paraná, 2006.

StoutLAND S.E. "The multiple Dimensions of Trust in resident/Police relations in Boston". Journal of Research in Crime and Deliquency, vol. 38, n³, p. 226.256, 2001.

SUPER, G. "The spectacle of crime in the 'new' South Africa: a historical perspective (1976-2004)". British Journal of Criminology, 50, p. 165-184, 2010.

TANKEBE, J. "Public confidence in the police: testing the effects of public experiences of police corruption in Ghana". British Journal of Criminology, 50, p. 296-319, 2010.

TAXMAN, F. S. et al. "Racial disparity and the legitimacy of the criminal justice system: exploring consequences for deterrence". Journal of Health Care for the Poor and Underserved, vol. 16, n 4, Supplement B, p. 57.77, 2005.

TYLER, T. R.; FAGAN, J. "Legitimacy and cooperation: why do people help the police fight crime in their communities?" Ohio State Journal of Criminal Law, p. 231-275, 2008.

TYLER, T. R.; WAKSLAK, C. J. "Profiling and police legitimacy: procedural justice, attributions of motive, and acceptance of police authority". Criminology, vol. 42, n² 2, p. 253-281, 2004.

TYLER, T R. "Policing in black and white: ethnic group differences in trust and confidence in the police". Police Quarterly, p. 322.342, Sept. 2005.

WaCQuant, L. "Crime e castigo nos Estados Unidos: de Nixon a Clinton". Revista de Sociologia e Política, Curitiba, n 13 , p. 39.50, 1999.

WARREN, P. Y. Race, class and trust: perceptions of the police in North Carolina. (Under the Direction of Donald Tomaskovic-Devey.), 2005.

WeitZer, R.; TUch, S. A. "Race and perceptions of police misconduct". Social Problems, vol. 51, n 3, p. 305-325, 2004 Wiatrowski, M.; Goldstone, J. A. "The ballot and the badge Democratic Policing". Journal of Democracy, vol. $21, n^{\circ} 2$, p. 79.92, Apr. 2010.

WOOD, R. "UK: the reality behind the 'knife crime' debate". Race \& Class, 52, p. 97-103, 2010.

WVS - World Values Survey, 2005 a 2008. Dísponível em: <www.worldvaluessurvey.org>. Acesso em: nov. 2011.

Zaluar, A. Da revolta ao crime S.A. São Paulo: Moderna, 1996.

Geélison F. Silva·geelisonfs@yahoo.com.br

Cláudio Beato · claudiobeato@crisp.ufmg.br

Submetido à publicação em outubro de 2011. Versão final aprovada em abril de 2013. 